\title{
Review of magnetic nanostructures grown by Focused Electron Beam Induced Deposition (FEBID)
}

\author{
J.M. De Teresa ${ }^{1,2,3, *}$, A. Fernández-Pacheco ${ }^{4}$, R. Córdoba ${ }^{1,2,3}$, L. Serrano-Ramón ${ }^{1,2,3}$, S. \\ Sangiao $^{2,3}$, M. R. Ibarra ${ }^{2,3}$ \\ ${ }^{1}$ Instituto de Ciencia de los Materiales de Aragón, CSIC-Universidad de Zaragoza, 50009 \\ Zaragoza (Spain) \\ ${ }^{2}$ Laboratorio de Microscopías Avanzadas (LMA), Instituto de Nanociencia de Aragón, \\ Universidad de Zaragoza, 50018 Zaragoza (Spain) \\ ${ }^{3}$ Departamento de Física de la Materia Condensada, Facultad de Ciencias, Universidad de \\ Zaragoza, 50009 Zaragoza (Spain) \\ ${ }^{4}$ Cavendish Laboratory, University of Cambridge. JJ Thomson Avenue, Cambridge UK CB3 \\ OHE (U.K.) \\ *Corresponding author: deteresa@unizar.es
}

\begin{abstract}
:
We review the current status of the use of focused electron beam induced deposition (FEBID) for the growth of magnetic nanostructures. This technique relies on the local dissociation of a precursor gas by means of an electron beam. The most promising results have been obtained using the $\mathrm{Co}_{2}(\mathrm{CO})_{8}$ precursor, where the Co content in the grown nanodeposited material can be tailored up to more than 95\%. Functional behaviour of these Co nanodeposits has been observed in applications such as arrays of magnetic dots for information storage and catalytic growth, magnetic tips for scanning probe microscopes, nano-Hall sensors for bead detection, nano-actuated magnetomechanical systems and
\end{abstract}


nanowires for domain-wall manipulation. The review also covers interesting results observed in Fe-based and alloyed nanodeposits. Advantages and disadvantages of FEBID for the growth of magnetic nanostructures are discussed in the article as well as possible future directions in this field.

Keywords: nanomagnetism, beam induced deposition, FEBID, magnetic nanostructures, nanolithography

\section{Contents:}

1. Introduction

1.1 Magnetic nanostructures

1.2 FEBID technique

1.3 Gas precursors for magnetic nanodeposits: overview

2. Co nanostructures by FEBID

2.1 Composition and microstructure

2.2 Magnetic and electrical properties

2.3 High-resolution and densely-packed Co nanostructures

2.4 Ion irradiation effects

2.5 Three-dimensional Co nanostructures

3. Fe nanostructures by FEBID

3.1 Composition and microstructure

3.2 Magnetic and electrical properties

$3.3 \mathrm{Fe}$ deposits in ultra-high-vacuum conditions

4. Ni and alloyed nanostructures by FEBID

4.1 Ni nanostructures

4.2 Co and Fe alloys

5. Applications of magnetic nanodeposits by FEBID

5.1 Magnetic dots for magnetic storage and catalytic growth

5.2 Growth of MFM and FMRFM tips

5.3 Nano-Hall sensors for bead detection

5.4 Nanowires in 2D and 3D for domain-wall manipulation

5.5 Spintronics and nanomagnetism

5.6 Nano-magnetic logic

5.7 Combination of magnetic deposits with superconductors

6. Summary and outlook 


\section{Introduction}

\subsection{Magnetic nanostructures}

The field of nanomagnetism is nowadays one of the most active topics in condensed-matter and materials-science research, offering many opportunities (1). Successful applications of magnetic nanostructures have been found for instance in high-density information storage and magnetic sensing (2). One of the key events in this development was the discovery of giant magnetoresistance in magnetic nanostructures $(3,4)$, awarded with the Nobel prize in Physics in $2007(5,6)$, which opened the field of Spintronics. The magnetoresistance effect is applied for the sensitive detection of small stray fields produced by tiny magnetic information bits or magnetic beads and in non-volatile magnetic memories (7).

Another relevant application of magnetic nanostructures has been proposed, though not yet realized, based on the manipulation of domain walls in magnetic nanowires. Thus, the racetrack memory proposed by Parkin et al. (8) and the magnetic logic proposed by Allwood et al. (9) are promising applications based on the fast movement (in the scale of the nanosecond) of magnetic domain walls triggered by magnetic fields or current pulses. Intense research is developed at present aiming to produce domain-wall manipulation by spin-torque effects via injection of a spin-polarized current (10). Furthermore, this spintorque mechanism can bring about the magnetization precession in certain conditions, producing the emission of radio-frequency waves with application as RF oscillators in telecommunication devices (11).

Another emergent field is that of magnetic biosensing, where magnetic nanoparticles tag biorecognition events and are detected by magnetic sensors such as giant or tunnel magnetoresistance sensors (12) or planar Hall sensors (13). From the detected signal, it is possible to obtain a quantitative determination of the concentration of a targeted analyte 
(virus, hormone, enzyme, DNA strand, etc.) (14). Also in life-sciences applications, arrays of highly-sensitive magnetic sensors are being developed for detection of the heart and brain activity (15).

Most working devices in the field of magnetic nanostructures rely for their creation on a top-down approach. This implies the use of thin-film growth techniques and/or microand nano-lithography techniques $(16,17)$. The methods of choice should address crucial aspects such as resolution, roughness, shape, materials involved, cost, etc. For the growth of magnetic films by physical techniques, sputtering is usually preferred, even though thermal or electron-beam evaporation, molecular beam epitaxy and pulsed laser deposition are also frequently used (18). With respect to the lithography techniques used, optical lithography is normally preferred down to the micron scale and electron-beam lithography below the micron scale (17). Optical lithography relies on UV-sensitive light resists and is indeed able to reach resolution better than $22 \mathrm{~nm}$ in the state-of-the-art steppers used in the Semiconductor industry, but their huge cost impedes the use at the laboratory level. Electron beam lithography relies on electron-sensitive resists spun onto the sample and submitted to electron beam irradiation inside a Scanning Electron Microscope (SEM). Ion milling or liftoff processes permit to define nanostructures in the range of $100 \mathrm{~nm}$ and in some favourable cases down to $10 \mathrm{~nm}$. However, some of the involved steps are critical and the final sample features can be far from ideal and affect the device functionality (19). In order to circumvent the use of resists and multiple-step lithography processes, direct patterning by focused-ionbeam is not rare, but this technique can strongly modify the magnetic properties of the materials, restricting its use (20). Nanoimprinting (and related techniques) has the potential to produce high throughput, thus being recommended for industrial applications, but the mold has to be grown with another lithography technique. 
It is in this context that Focused Electron Beam Induced Deposition (FEBID) of magnetic materials is becoming a promising route for the direct growth of magnetic nanostructures in a single step. As will be developed along the next sections, this technique does not involve the use of resists, etching or lift-off processes, whereas maintaining the high lateral resolution down to the nanometric scale and being able to grow materials with appropriate magnetic properties.

\subsection{FEBID technique}

FEBID can be considered a beam-assisted Chemical Vapour Deposition (CVD) technique. But, in this case, the energy required to dissociate the precursor molecules is not thermally provided, as occurs in CVD, but by electron beam irradiation, whilst the substrate is generally maintained at room temperature. The precursor molecules are delivered onto the substrate surface by means of a nearby gas-injection system and the focused beam is scanned on the substrate, creating a deposit with the same shape of the beam scanning. Figure 1 illustrates this process.

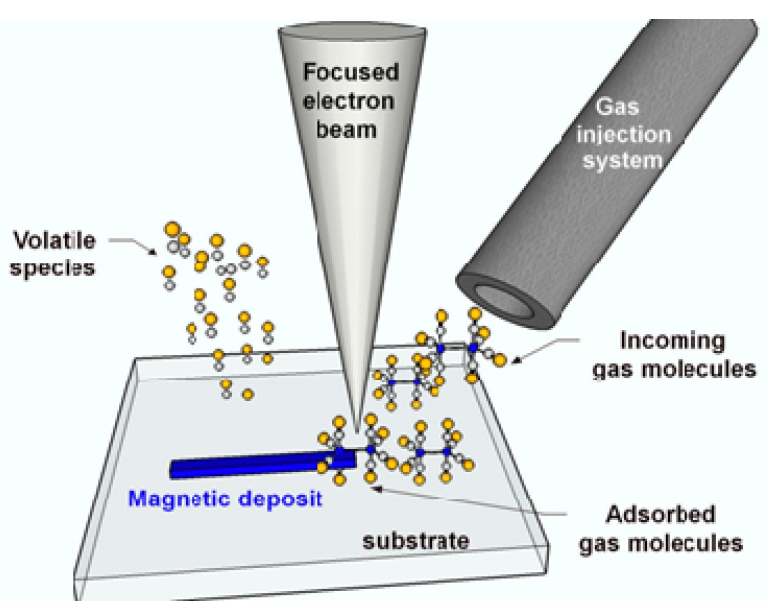

Figure 1. Sketch of Focused Electron Beam Induced Deposition (FEBID). This is an electron-assisted chemical growth technique giving rise to high-resolution patterning in a single step. The precursor molecules are locally dissociated by a Scanning Electron Microscope. 
A few review articles (21-24) and books (25) on the FEBID technique are available and the reader is referred to such references for deeper understanding of this technique. An important aspect to consider is that the energy of the bonds in the precursor molecules is in the range of a few $\mathrm{eV}$, implying that their dissociation is generally governed by the secondary electrons produced in the substrate and the growing structure (26-28). This phenomenon is important for the understanding of the achievable lateral resolution and the appearance of a thin halo grown around the main deposit, as will be shown in the following sections of this review.

We note that, prior to the present review article, other publications have partially addressed the specific topic of magnetic deposits with a relative broad perspective $(29,30)$. However, such publications are not comprehensive review articles of the topic. Here, we aim to include references to all published work so far on the topic of magnetic deposits by FEBID technique.

\subsection{Gas precursors for magnetic nanodeposits}

The precursors used so far for magnetic nanodeposits by FEBID are collected in Table I together with all the references that have reported their experimental use. The number of these precursors is limited to a few but the number of references has strongly increased during last years. It should be mentioned that practical issues limit the availability of precursors for FEBID, as recently discussed by J. J. L. Mulders (31). For the sake of completeness, we include in Table I references where these magnetic precursors were also used for Focused Ion Beam Induced Deposition (FIBID), as well as for the growth of magnetic alloys with two precursors simultaneously injected. In the case of cobalt, $\mathrm{Co}_{2}(\mathbf{C O})_{8}$ is by far the precursor gas commonly used $(29,30,32-93)$. The advantage of this precursor is its low spontaneous dissociation temperature, around $100^{\circ} \mathrm{C}(94)$. This indicates 
relative low bonding energies in this molecule, which is favorable for its dissociation by electron irradiation in order to attain high metallic content. In fact, in 2002 the growth of Co tips on AFM cantilevers by FEBID using that precursor was reported and magnetic imaging of a hard disk was realized (34-36). The reported Co content reached $80 \%(34,41)$, and that large value was mainly ascribed to heating effects when using high beam current. Recent studies enlarged the expectations of this precursor, as 95\% Co content was reported when the growth was performed under high electron beam current and using a field-emission electron gun (42). Heating effects were definitely found to be important for the degree of precursor dissociation $(46,57)$, although other effects are competing $(45,60)$ making difficult to disentangle the role of all contributing effects. The good news is that using low electron beam currents it is also possible to obtain deposits at room temperature with Co content greater than $90 \%(60)$. Another cobalt-based precursor, $\mathbf{C o}(\mathbf{C O})_{3} \mathbf{N O}$, has been studied experimentally $(34,57,95-100)$ but does not seem advantageous with respect to $\mathrm{Co}_{2}(\mathrm{CO})_{8}$ regarding the achievable Co content.

In the case of Fe-based nanodeposits, several carbonyl-based precursors have been used such as $\mathbf{F e}(\mathbf{C O})_{5}, \mathbf{F e}_{3}(\mathbf{C O})_{12}, \mathbf{F e}_{2}(\mathbf{C O})_{9}$ and $\mathbf{F e}\left(\mathbf{C}_{5} \mathbf{H}_{5}\right)_{2}$. In 1987, Kunz and Mayer reported the growth of $150 \mathrm{~nm}$-wide iron wires by FEBID using the $\mathrm{Fe}(\mathrm{CO})_{5}$ precursor $(101$, 102). The composition of the nanodeposits was not shown in that work. The spontaneous thermal decomposition of $\mathrm{Fe}(\mathrm{CO})_{5}$ on $\mathrm{Si}$ was found at $250{ }^{\circ} \mathrm{C}$, and strong catalytic effects were reported in that work. Only in 2004, Fe deposits by FEBID were again reported by Shimojo et al., who described the formation of alpha-Fe and some carbides using the $\mathrm{Fe}(\mathrm{CO})_{5}$ precursor and performing an annealing process (103). Since that moment, literature on Fe-based nanostructures is more abundant and, for example, Zhang et al. reported the growth of alpha-Fe nanocrystals on carbon grids (104). In 2005, Bruk et al. reported the use of $\mathrm{Fe}_{3}(\mathrm{CO})_{12}(105)$, whereas in 2006 Takeguchi et al. reported the use of $\mathrm{Fe}\left(\mathrm{C}_{5} \mathrm{H}_{5}\right)_{2}(106)$ 
and Lavrijsen et al. reported the use of $\mathrm{Fe}_{2}(\mathrm{CO})_{9}$ in 2011 (107). Working under high-vacuum conditions, standard for SEM chambers, the Fe content using all the available Fe precursors seems limited to about $80 \%$ before annealing or purification processes (108) although the use of ultra-high-vacuum conditions has allowed Luckasczyk et al. to grow Fe nanostructures on $\mathrm{Si}$ substrates using the $\mathrm{Fe}(\mathrm{CO})_{5}$ precursor with $\mathrm{Fe}$ content above $95 \%$ (109).

Recently, a heteronuclear precursor, $\mathrm{HFeCo}_{\mathbf{3}}(\mathbf{C O})_{12}$, has been used with total $\mathrm{Fe}$ plus Co content around 80\% (110). For Ni deposition, $\mathbf{N i}\left(\mathbf{C}_{5} \mathbf{H}_{4} \mathbf{C H}_{3}\right)_{2}$ and $\mathbf{N i}\left(\mathbf{P F}_{3}\right)_{4}$ have been used for the growth of Ni-based deposits whereas $\mathrm{Ni}(\mathrm{CO})_{4}$ has been discarded for its toxicity $(111,112)$. 
Table I: References reporting magnetic-based nano-deposits grown by FEBID, classified by the precursor used and the year of publication. A few existing examples where the growth was carried out by FIBID have been included as well, and marked with an asterisk.

\begin{tabular}{|c|c|}
\hline Precursor & References \\
\hline $\mathrm{Co}_{2}(\mathrm{CO})_{8}$ & 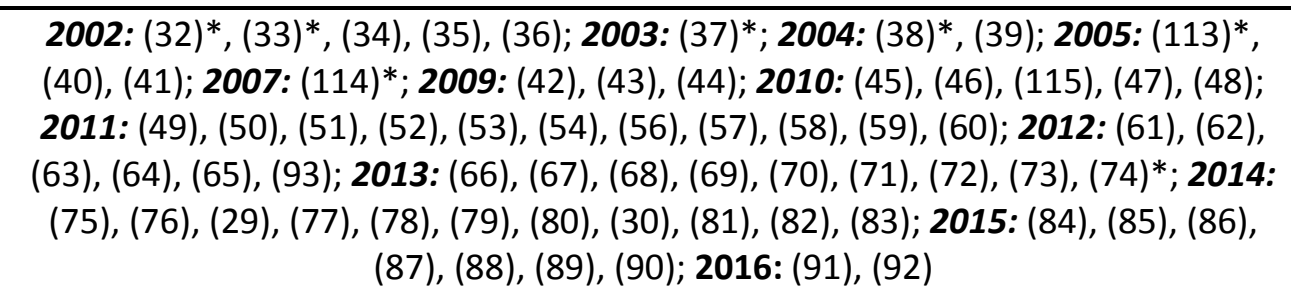 \\
\hline $\mathrm{Co}(\mathrm{CO})_{3} \mathrm{NO}$ & 2002: (34); 2009: (100); 2011: (95), (96), (57); 2013: (98), (97); 2014: (99) \\
\hline $\mathrm{Fe}(\mathrm{CO})_{5}$ & 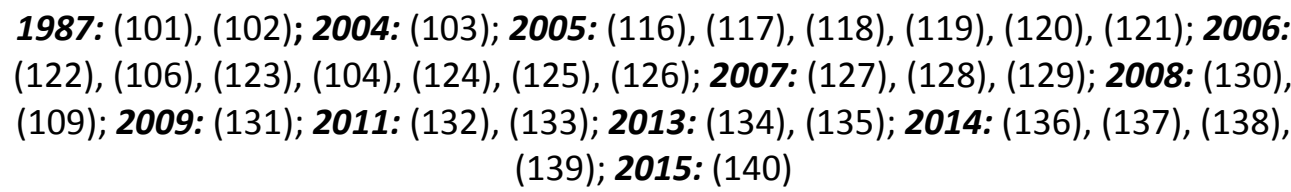 \\
\hline $\mathrm{Fe}_{3}(\mathrm{CO})_{12}$ & 2005: (105) \\
\hline $\mathrm{Fe}\left(\mathrm{C}_{5} \mathrm{H}_{5}\right)_{2}$ & 2005: $(113)^{*} ;$ 2006: (123); 2007: (141)* \\
\hline $\mathrm{Fe}_{2}(\mathrm{CO})_{9}$ & 2011: (107); 2012: (142); 2014: (143); 2015: (144) \\
\hline $\mathrm{HFeCO}_{3}(\mathrm{CO})_{12}$ & 2015: (110) \\
\hline $\mathrm{Ni}\left(\mathrm{C}_{5} \mathrm{H}_{4} \mathrm{CH}_{3}\right)_{2}$ & 2007: (111); 2016:(112) \\
\hline $\mathrm{Ni}\left(\mathrm{PF}_{3}\right)_{4}$ & 2007:(111) \\
\hline
\end{tabular}

\section{Cobalt nanostructures by FEBID}

\subsection{Composition and microstructure}

The main parameters determining the Co content in $\mathrm{Co}_{2}(\mathrm{CO})_{8}$ will be discussed hereafter. The first reports, dating back to 2002, already stressed the influence of the electron beam current in the Co content (34). The use of high beam currents ( $\mu \mathrm{A}$ range) permitted to reach Co contents up to $80 \%$, but killing the lateral resolution due to the corresponding micrometric beam diameter (41). Substrate heating up to $58^{\circ} \mathrm{C}$ at $3 \mu \mathrm{A}$ beam current was put 
forward to explain such dependence. The microstructure of the deposits was observed to be composed of small (few $\mathrm{nm}$ ) polycrystalline Co grains immersed in a carbonaceous matrix $(34,41)$. Fernández-Pacheco et al. found that Co content up to $95 \%$ was feasible using a field-emission electron gun, as shown in figure 2(a). At a low beam current of $0.1 \mathrm{nA}$, the Co content was found to be $80 \%$ but rose to $95 \%$ when the beam current became greater than $1 \mathrm{nA}$ (42). Beam currents in the $\mathrm{nA}$ range impose limitations in lateral resolution. Reaching resolutions below $100 \mathrm{~nm}$ is in general not possible with such current values. However, by means of a heater, Córdoba et al. showed that it is possible to obtain high Co content (above 90\%) if the substrate is heated above $100^{\circ} \mathrm{C}$ even for beam currents as low as $44 \mathrm{pA}$, as shown in figure 2(b) (46). Substrate heating was expected to favor precursor dissociation, as later confirmed by Mulders et al. (57). This is in good agreement with the expected low dissociation energy of bonds in the $\mathrm{Co}_{2}(\mathrm{CO})_{8}$ molecule, which is thermally decomposed around that temperature $(46,57,94)$. 
(a)

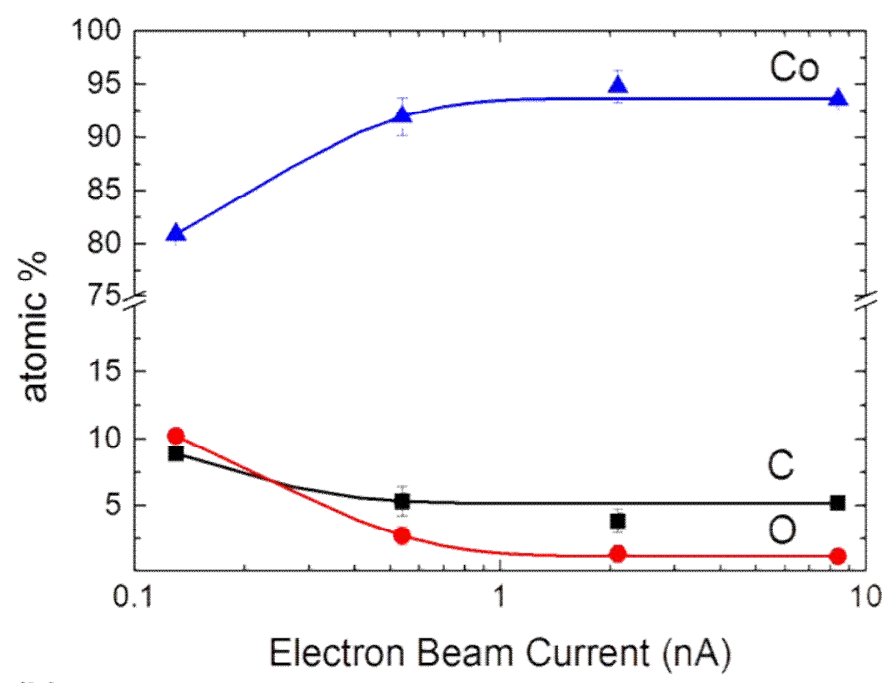

(b)

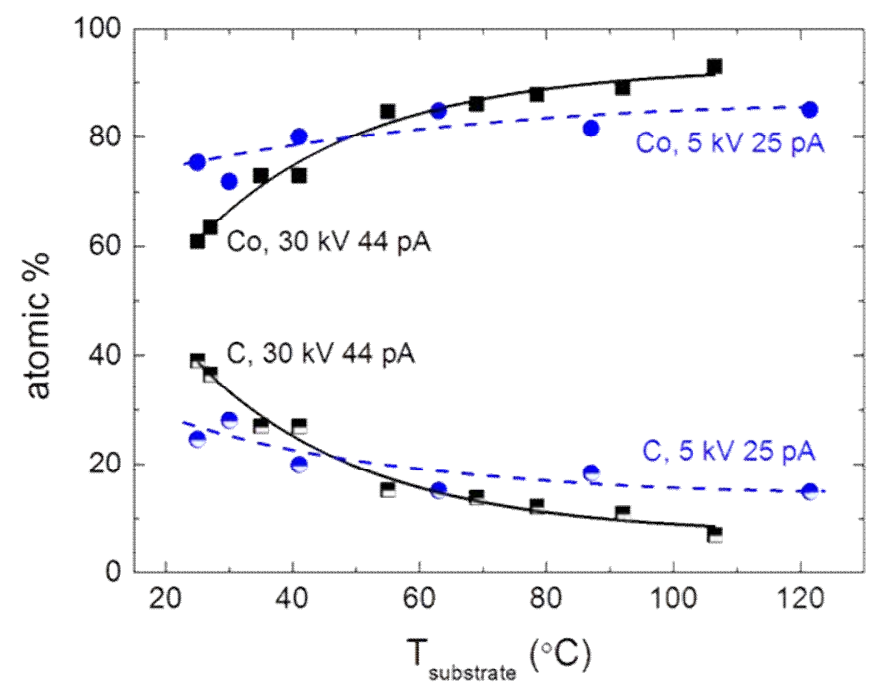

Figure 2. (a) Atomic percentage of $\mathrm{Co}, \mathrm{C}$ and $\mathrm{O}$ as a function of the electron-beam current in $\mathrm{Co}$ nanodeposits grown at $10 \mathrm{kV}$ using $\mathrm{Co}_{2}(\mathrm{CO})_{8}$ as the precursor gas. Reprinted with permission from A Fernández-Pacheco et al 2009 J. Phys. D: Appl. Phys. 42055005. Copyright (2009). DOI: 10.1088/0022-3727/42/5/055005; deteresa@unizar.es. (b) Atomic percentage of $\mathrm{Co}$ and $\mathrm{C}$ as a function of the substrate temperature in Co nanopillars grown at $30 \mathrm{keV}, 44 \mathrm{pA}$ and $5 \mathrm{keV}, 25 \mathrm{pA}$. Reprinted from Microelectronic Engineering, 87, $R$. Córdoba et al., High-purity cobalt nanostructures grown by focused-electron-beam-induced deposition at low current, 1550-1553, Copyright (2010), with permission from Elsevier. rocorcas@unizar.es. 
Despite the importance of thermal effects, there are other relevant growth parameters in FEBID impacting the final metal content of the deposits. For example, Bernau et al. found that residual hydrocarbon molecules in the chamber can contribute to the deposit composition but can be controlled by variations in the electron dwell time (45). As an example, figure 3 shows experiments in which the use of short dwell time gives rise to significant hydrocarbon decomposition compared to carbonyl decomposition, leading to only $20 \%$ Co content in the deposit. However, there is lack of enough hydrocarbon replenishment when the dwell time is long, which increases the Co content three times (45).

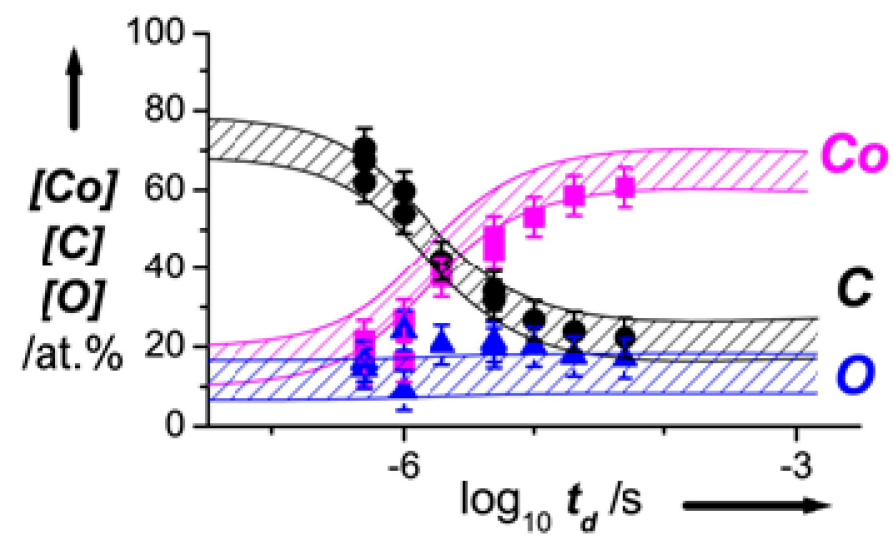

Figure 3. Atomic percentage of $\mathrm{Co}, \mathrm{C}$ and $\mathrm{O}$ versus dwell time $\mathrm{t}_{\mathrm{d}}(25 \mathrm{keV}, 1 \mathrm{nA}, 10 \mathrm{~ms}$ refresh time) in Co-C deposits grown in the presence of two adsorbates $\left[\mathrm{Co}_{2}(\mathrm{CO})_{8}\right]$ and hydrocarbon. Reprinted from L. Bernau et al., Angewandte Chemie, 49, 8880-8884, Copyright (2010), with permission from WILEY.Ivo.Utke@empa.ch

Additionally, Serrano-Ramón et al. have shown that, besides the dwell time, the precursor flux is a tuning parameter of the metal content (60). As shown in figure 4 , there is an optimum precursor flux that maximizes the Co content. The explanation is that at low precursor gas flux (precursor-limited regime) there is a significant amount of chamber 
residual molecules that are decomposed compared to the number of Co molecules. Some atoms of such residual molecules become incorporated in the deposit. At high precursor flux, the amount of Co molecules outcomes the residual ones, and the probability of having more Co in the deposit increases. However, in this electron-limited regime, some bonds of the Co molecule cannot be dissociated, leading to $\mathrm{C}$ and $\mathrm{O}$ atoms in the deposit with origin in the $\mathrm{Co}_{2}(\mathrm{CO})_{8}$ molecule itself. Thus, an optimum value of the precursor flux, at the crossover between the precursor-limited and electron-limited regimes is found. In that situation, even for low beam currents such as $21 \mathrm{pA}$ (allowing lateral resolution of $30 \mathrm{~nm}$ ) Co content greater than $90 \%$ is found (60). Similarly, Wachter et al. have reported the advantage of Co growth at the crossover between the precursor-limited and electron-limited regimes (82). Summarizing, thermal effects are not necessary to achieve high Co content as thought in the first studies, which makes possible to obtain simultaneously high Co content and lateral resolution.

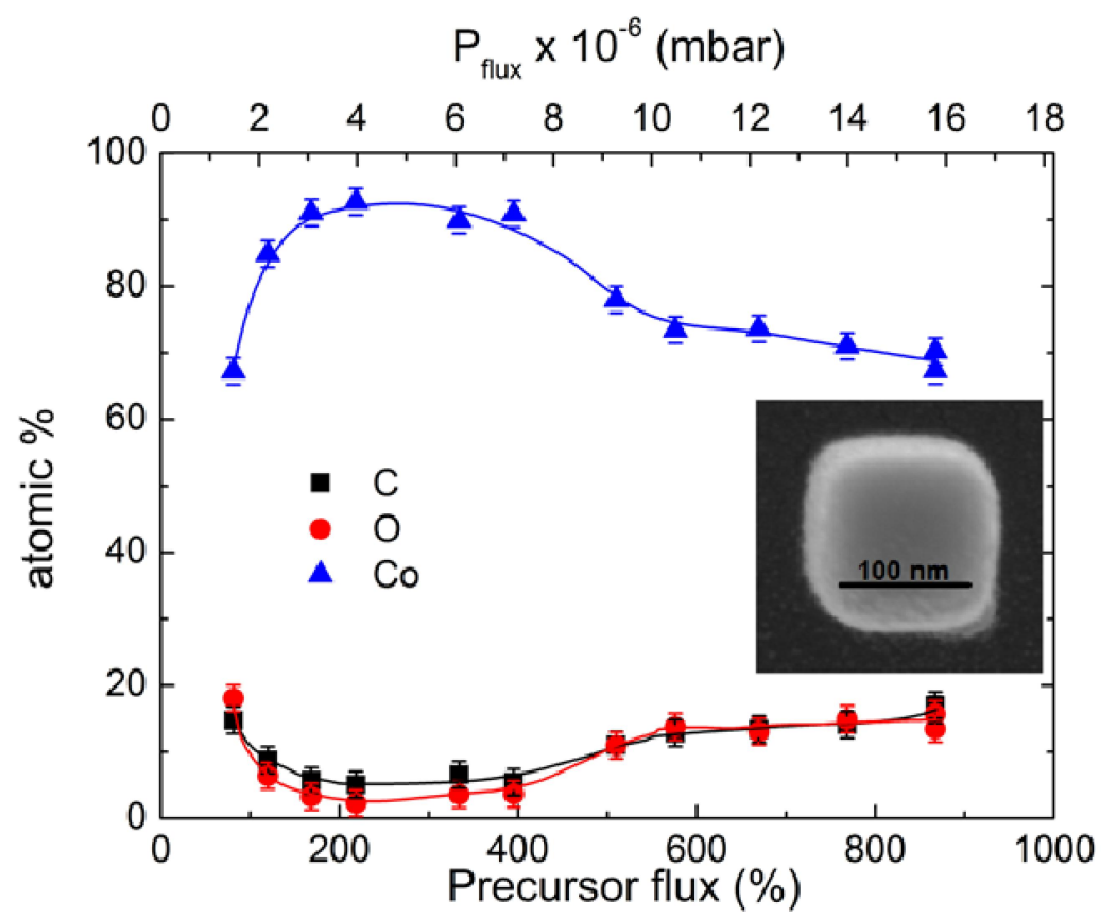

Figure 4. Atomic percentage of $\mathrm{Co}, \mathrm{C}$ and $\mathrm{O}$ as a function of the $\mathrm{Co}_{2}(\mathrm{CO})_{8}$ precursor flux in nanodeposits grown at $3 \mathrm{kV}$ and $21 \mathrm{pA}$. An SEM image of the typical cobalt squares grown 
is shown in the inset. The relative change of precursor flux is here defined by the expression: Precursor flux $(\%)=100 \times\left(\mathrm{P}_{\text {process }}-\mathrm{P}_{\text {base }}\right) / \mathrm{P}_{\text {base. }}$ Reprinted with permission from ACS Nano, 2011, 5 (10), pp 7781-7787. Copyright (2011) American Chemical. deteresa@unizar.es.

In case that as-grown deposits present low Co content, it is possible to apply a postgrowth purification process to enhance the metal content. Begun et al. have investigated several treatments to find that the most effective one is the combination of $300^{\circ} \mathrm{C}, \mathrm{H}_{2}$ exposure and electron irradiation, which produces virtually-pure Co deposits from the surface down to a depth of $20 \mathrm{~nm}(84)$.

Regarding the microstructure of the Co deposits, detailed Transmission Electron Microscopy (TEM) studies on low-Co-content and high-Co-content deposits have shown their polycrystalline nature (50). The difference between both types of deposits is that lowCo-content ones present isolated 2-3 nm Co grains immersed in a carbonaceous matrix, whereas high-Co-content ones present a compact metal structure with 5-7 nm Co grains. Electron diffraction indicates that the crystallographic structure of such grains is a mixture of hexagonal-close-packed (hcp) and face-centered-cubic (fcc) ones (50). Gazzadi and Frabboni have recently shown that the application of large electrical current through Co nanowires produces structural changes, modifying the relative amount of hep and fcc grains (86).

As mentioned before, $\mathrm{Co}(\mathrm{CO})_{3} \mathrm{NO}$ precursor molecule has also been studied as an alternative to $\mathrm{Co}_{2}(\mathrm{CO})_{8}$ for Co deposition. Lau et al. found that high-current deposition from this precursor results in autocatalytic growth due to temperature rise (34). Gazzadi et al. (95, 96) as well as Mulders et al. (57) found that this precursor produces deposits with around $50 \%$ Co content. Gazzadi et al. performed annealing procedures up to $400^{\circ} \mathrm{C}$ finding that 


\subsection{Magnetic and electrical properties}

The magnetic and electrical functionality of Co nanostructures grown by FEBID will depend to a great extent on their composition and microstructure. In the previous section, we have noted that these can vary significantly amongst different growth conditions. As a summary, the set of results with $\mathrm{Co}_{2}(\mathrm{CO})_{8}$ as precursor indicates that deposits with high Co content (> 90\%) show metallic and ferromagnetic behavior, whereas deposits with low Co content $(<$ $80 \%$ ) show semiconducting and paramagnetic/super-paramagnetic behavior. Regarding electrical properties, Lau et al. found electrical resistivity values equal to $159 \mu \Omega \mathrm{cm}$ in those deposits with highest Co content (of $\approx 80 \%$ ), which is 25 times greater than pure Co (34). Fernández-Pacheco et al. found significantly lower resistivity values, of $40 \mu \Omega \mathrm{cm}$ at $300 \mathrm{~K}$, and $27 \mu \Omega \mathrm{cm}$ at $2 \mathrm{~K}$, in deposits with $95 \%$ Co (42). Figure 5 shows some of these results, including the temperature dependence of resistivity for this type of high-Co-content deposits (figure 5(a)) and the Hall effect (figure 5(b)), where two contributions, the anomalous Hall effect (proportional to the magnetization) and the ordinary Hall effect (linear with the magnetic field and depending on the number of carriers) are observed. Similar results have been observed in purified Co deposits, with metal content approaching $100 \%$ and resistivity value of $15 \mu \Omega \mathrm{cm}$ at low temperature (84). On the other hand, Co content below $80 \%$ in general gives rise to semiconducting behavior (42) and absence of clear separation of the ordinary and anomalous Hall effects (48). 

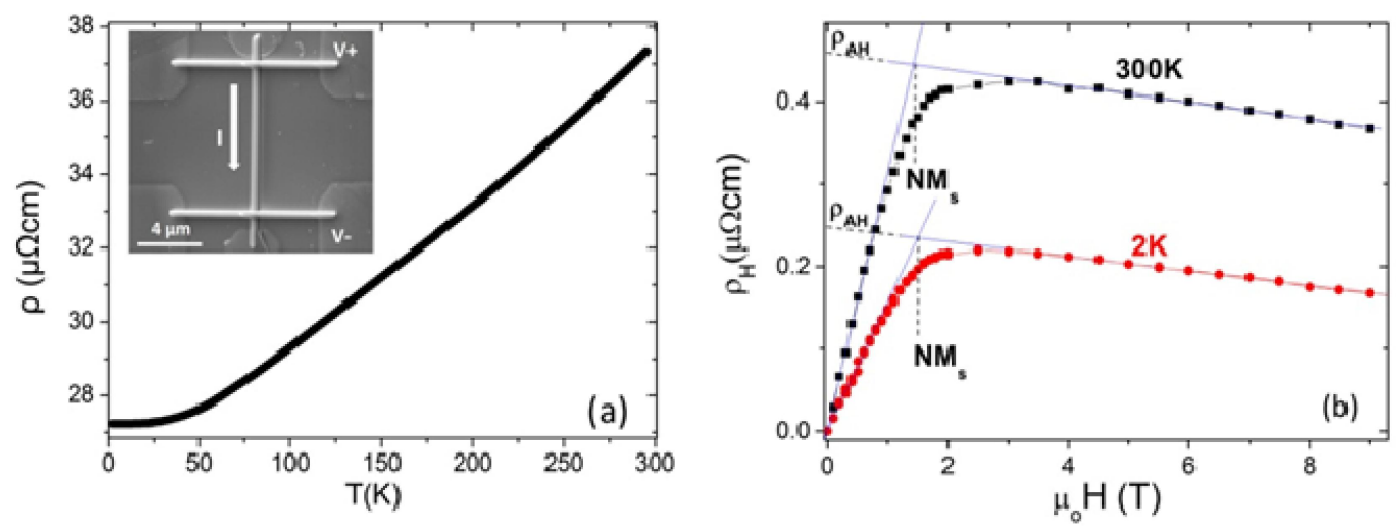

Figure 5. (a) Resistivity-vs-temperature measurement for the wire shown in the inset, grown by FEBID, showing metallic behaviour. (b) Hall effect for this wire, measured at $300 \mathrm{~K}$ and $2 \mathrm{~K}$. The indicated saturation field makes possible to obtain the saturation magnetization of the material. Reproduced with permission from "Magnetotransport properties of highquality cobalt nanowires grown by focused-electron-beam-induced deposition", by A. Fernández-Pacheco, et al, Journal of Physics D: Applied Physics 42, 055005 (2009). IOP Publishing Ltd.

Regarding the magnetic switching behavior of Co structures by FEBID, deposits with metal content above $90 \%$ display conventional ferromagnetic behavior. Given that these deposits are polycrystalline with a small $(5-7 \mathrm{~nm})$ grain size, the magnetocrystalline anisotropy is averaged to zero and shape anisotropy governs the magnetization reversal. This was demonstrated by Fernández-Pacheco et al. on Co wires with the same length and thickness but varying width by means of Magneto-optical Kerr Effect (MOKE) measurements. As shown in Figure 6, the coercive field becomes larger as the width decreases due to the increasing shape anisotropy (44). As a consequence, the coercive field is easily tunable through modification of the dimensions of the Co nanostructures, as later also observed by Nikulina et al. (64). 

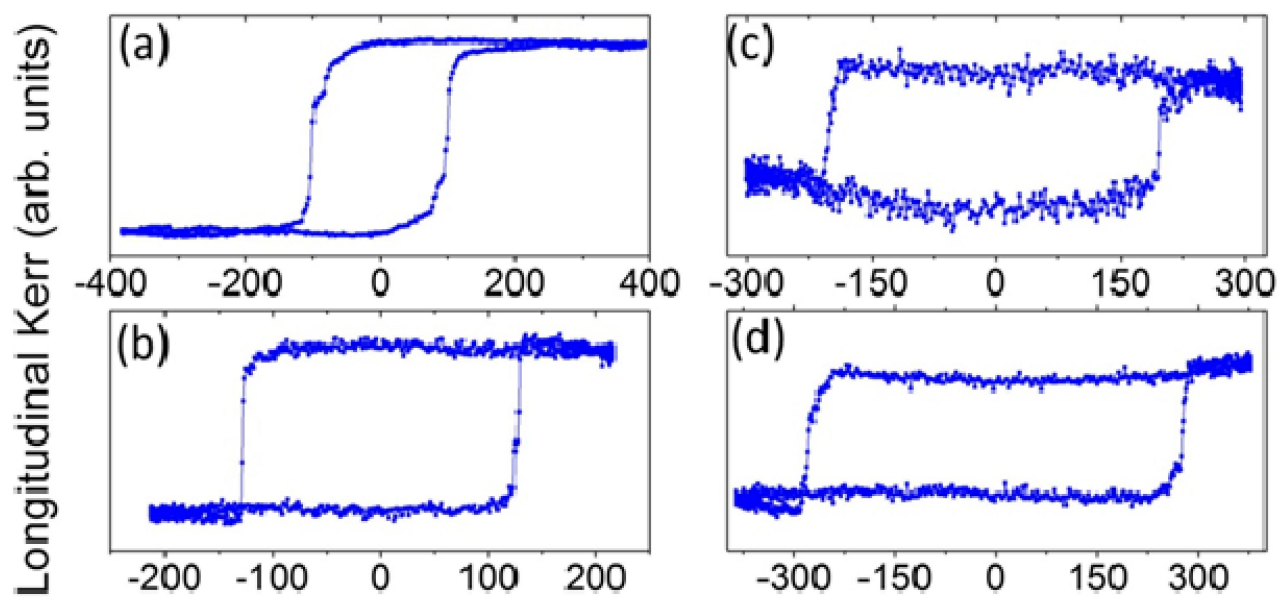

$\mathrm{H}(\mathrm{Oe})$

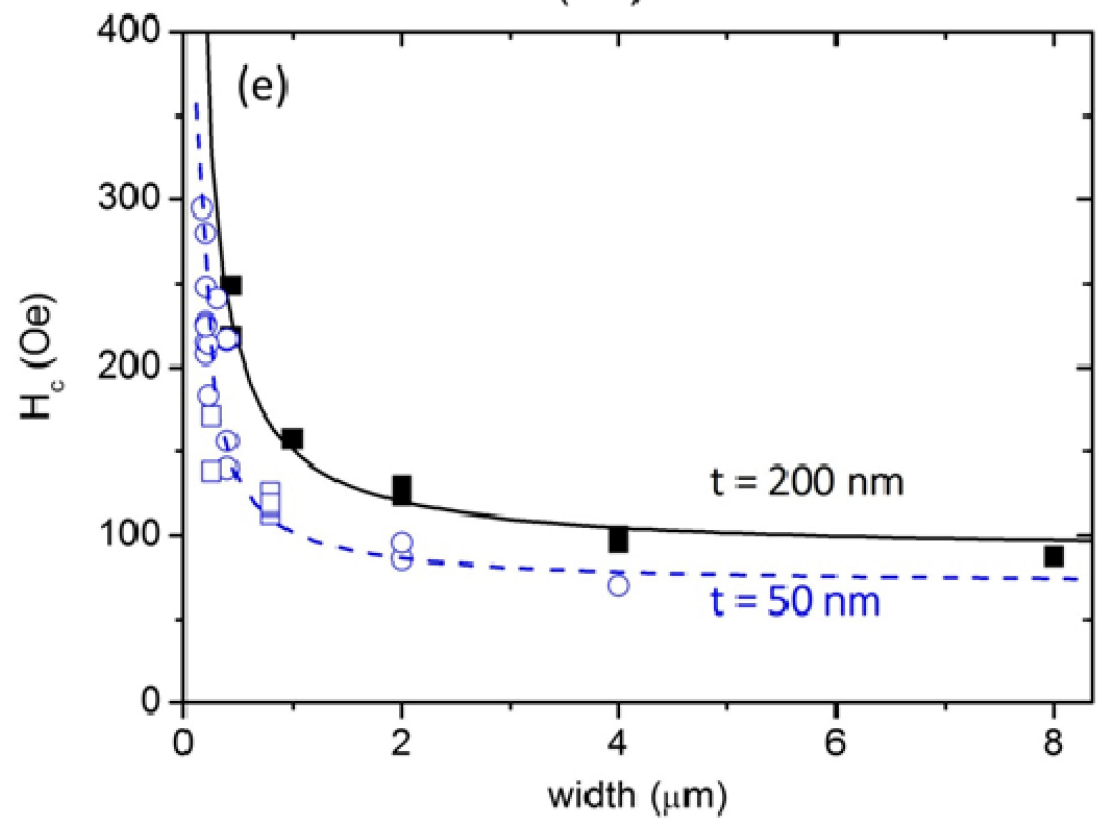

Figure 6. (a-d) MOKE hysteresis loops for Cobalt FEBID rectangles of different aspect ratios: $A R=1$ (a), 2 (b), 12 (c), 26 (d). (e) Coercivity of the rectangles as a function of its width, for two thicknesses, showing a 1/width dependence. Reproduced with permission from "Magnetization reversal in individual cobalt micro- and nanowires grown by focusedelectron-beam-induced-deposition", by A Fernández-Pacheco et al, Nanotechnology 20 (47), 475704 (2009). IOP Publishing Ltd. 
The same type of high-content Co nanowires gives very good contrast in Magnetic Force Microscopy (MFM) measurements (54, 55), which allows the microscopic investigation of the magnetic state of these Co nanostructures. As Figure 7 shows, the magnetic remanent state in these Co wires depends on the aspect ratio for fixed length, as expected when shape anisotropy dominates. For narrow wires (width smaller than $400 \mathrm{~nm}$ ), a mono-domain magnetic state occurs whereas magnetic domain walls are noticed in wider nanostructures (55).
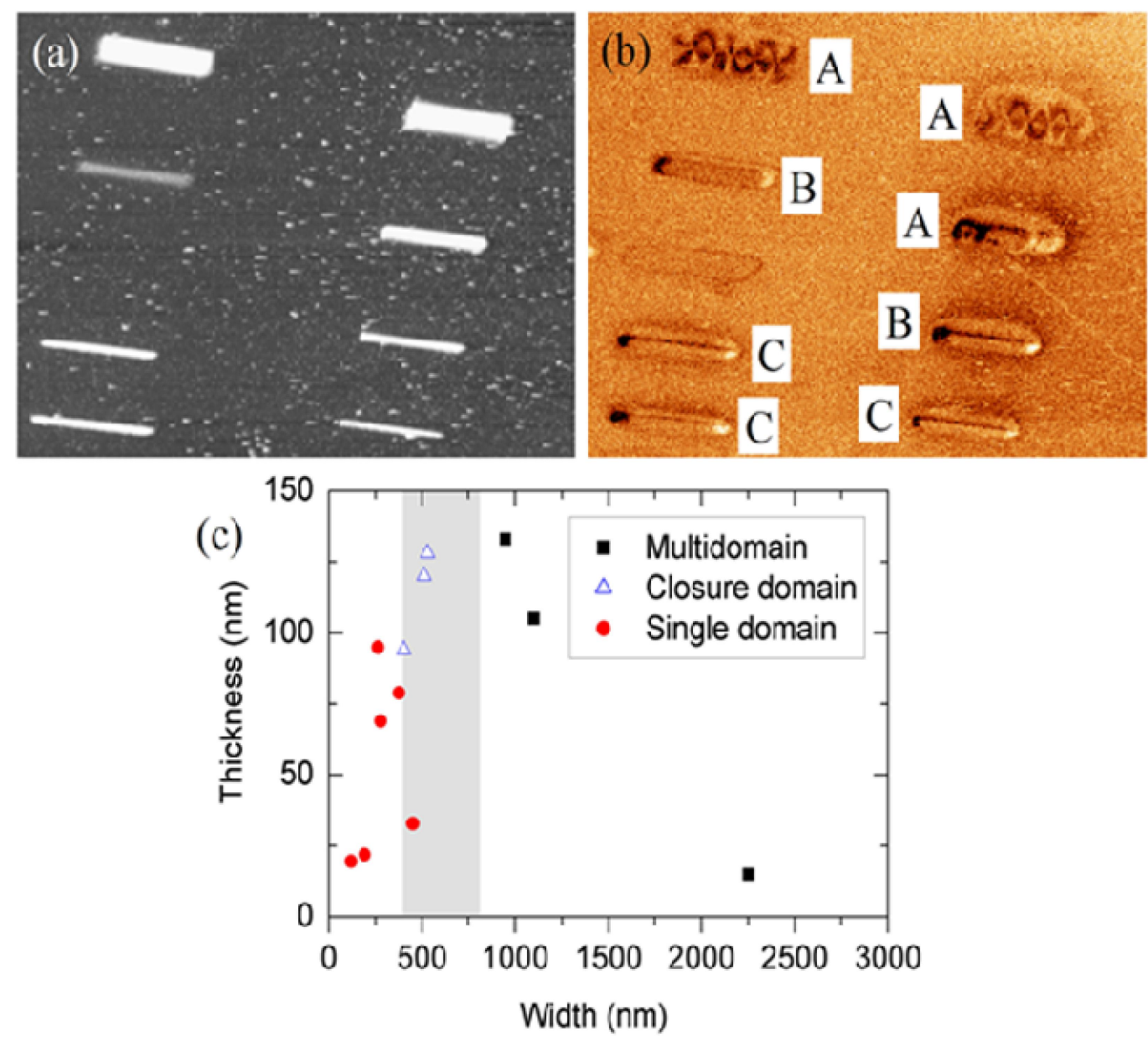

Figure 7. (a) Topography and (b) MFM image of an array of Co wires with varying width. Notice how the domain configuration is a function of the aspect ratio of the nanostructures (c) Wires domain configuration distribution as a function of their dimensions. Reproduced with permission from M. Jaafar et al., Nanos. Res. Lett. 6, 407 (2011). Springer. 
Electron holography and Lorentz microscopy inside a TEM have been carried out in order to investigate the magnetic state of Co nanowires grown by FEBID on $\mathrm{Si}_{3} \mathrm{~N}_{4}$ membranes $(70,71)$. The observed magnetic states are in good agreement with the performed micro-magnetic simulations in standard polycrystalline Co nanowires (71).

On the other hand, low-Co-content deposits display super-paramagnetic behavior, in good agreement with their microstructure, formed by small isolated grains within a nonmagnetic carbonaceous matrix, which, incidentally, is useful for the fabrication of Hall sensors with large sensitivity as shown by Gabureac et al. (48).

The work by Gazzadi et al. indicates that Co deposits grown with the $\mathrm{Co}(\mathrm{CO})_{3} \mathrm{NO}$ precursor are very resistive $(6000 \mu \Omega \mathrm{cm})$, but an annealing procedure at $400{ }^{\circ} \mathrm{C}$ gives rise to Co nanowires with low resistivity at room temperature, $60 \mu \Omega \mathrm{cm}$, and metallic behavior as a function of temperature (96).

\subsection{High-resolution and densely-packed cobalt nanostructures}

As introduced in section 2.1, it was soon understood that although the use of high beam current ( $\mu \mathrm{A}$ range) could produce Co deposits with high metal content, the lateral resolution was in that case compromised (34) due to the increasing electron beam size with increasing beam current. This effect adds to the production of secondary electrons beyond the impact point, due to the interaction of the primary electron beam with the growing deposit as well as with the substrate, which further limits the lateral resolution $(26,145)$. The first approach to improve the lateral resolution is consequently the growth under low electron beam currents, in the pA range, with beam diameters of only a few nm. As discussed in 2.1 , for the $\mathrm{Co}_{2}(\mathrm{CO})_{8}$ precursor, there are appropriate combinations of precursor flux and dwell time that permit the growth of Co nanostructures with high Co content $(\approx 90 \%)$ and lateral resolution. In Figure 8, the best lateral resolution obtained by Serrano-Ramón et al. $(\approx 30$ 
$\mathrm{nm}$ ) is observed (60). In that figure, some nanowires and Hall crosses are displayed, which correspond to the optimum growth conditions for concomitant high Co content and lateral resolution.
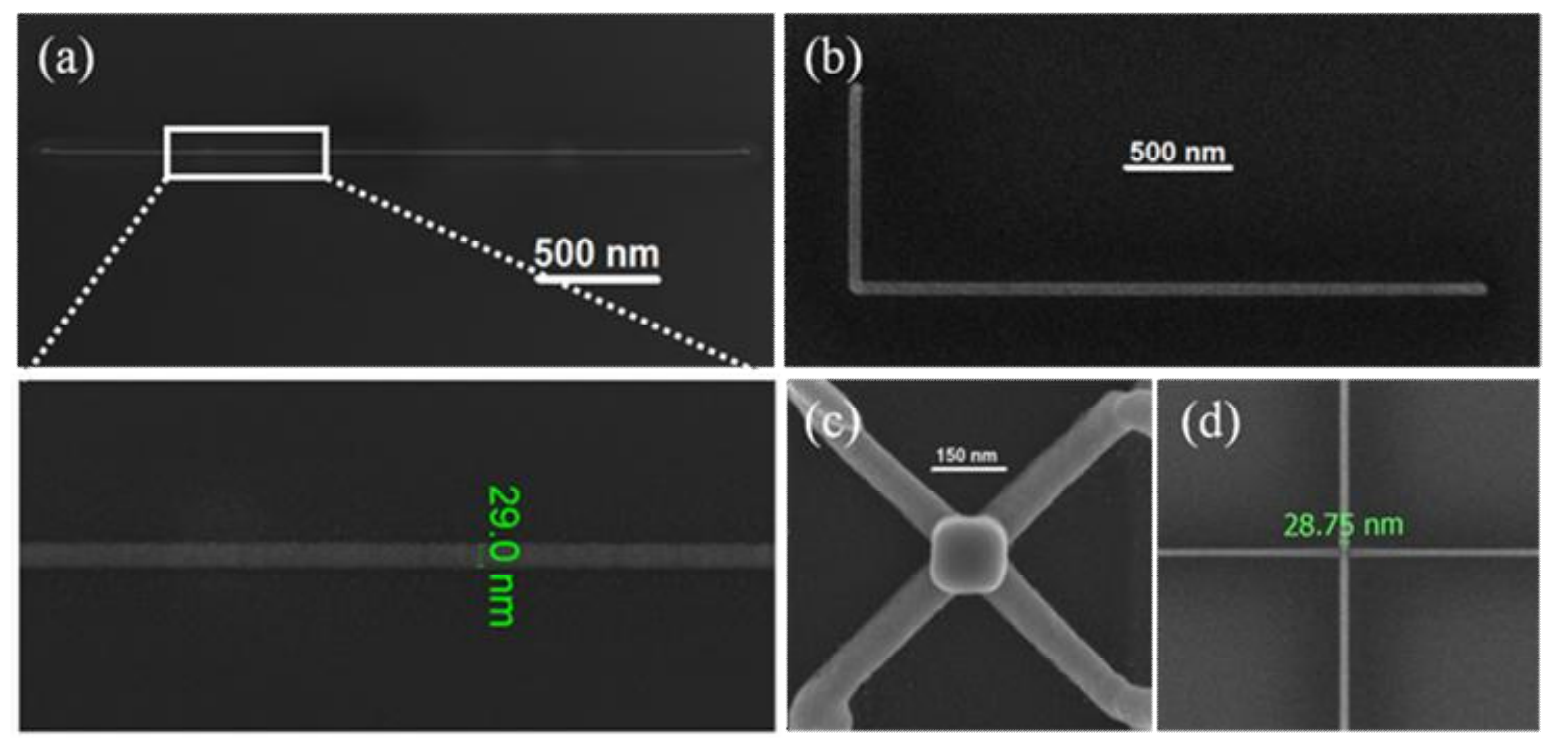

Figure 8. (a) SEM image of a cobalt nanowire with dimensions of $3 \mu \mathrm{m}$ in length, $29 \mathrm{~nm}$ in width, and $30 \mathrm{~nm}$ in thickness grown at $3 \mathrm{kV}, 21 \mathrm{pA}$ (image taken at tilting angle of 52). A zoom-in image is shown in the inset. (b) SEM image of a cobalt nanostructure (L-shape) with dimensions of $3 \mu \mathrm{m}$ in length for the horizontal part and $1 \mu \mathrm{m}$ in length for the perpendicular part, $40 \mathrm{~nm}$ in width, and $30 \mathrm{~nm}$ in thickness, grown at $3 \mathrm{kV}, 21 \mathrm{pA}$. (c) SEM image of a Co Hall sensor based on four independent $75 \mathrm{~nm}$ wide Co lines and a central 150 nm-wide square as active area. (d) SEM image of a cobalt Hall cross with a width less than $30 \mathrm{~nm}$. Reprinted with permission from ACS Nano, 2011, 5 (10), pp 7781-7787. Copyright (2011) American Chemical.deteresa@unizar.es.

A very good lateral resolution has been reached even on non-conventional substrates such as flexible and transparent polycarbonate ones (87). As can be noticed in Figure 9, sub$100 \mathrm{~nm}$ Co nanowires, with high Co content and metallic behavior, have been grown on this 
non-conductive substrate, opening new avenues for applications of this material in flexible electronics or magnetic sensing (87).

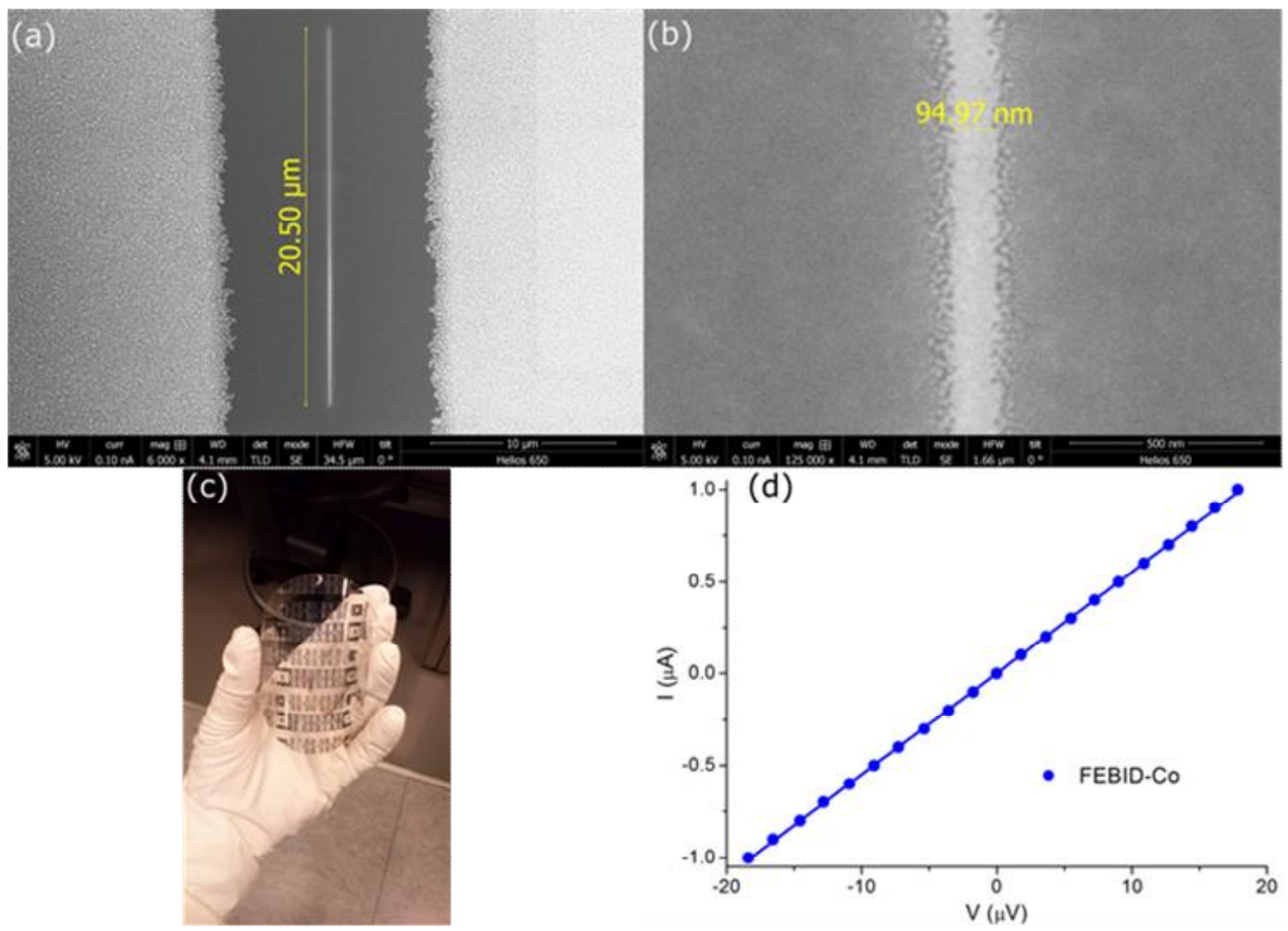

Figure 9. $(\mathrm{a}, \mathrm{b})$ Scanning electron micrographs of Co nanowires grown by FEBID on flexible and transpartent polycarbonate substrates. (c) Picture of a polycarbonate substrate patterned by means of optical lithography to allow electrical measurements. (d) Current vs voltage characteristic of a Co nanowire grown by FEBID on polycarbonate. Reproduced with permission from P. Peinado et al., ACS Nano, 2015, 9(6), 6139-6146. Copyright (2015) American Chemical Society.

An important issue in the area of nano-magnetism is the feasibility to integrate many nanostructures in a small space. This is for example the case for magnetic memories and logic applications. On the one hand, the FEBID technique is known to have a potential lateral resolution of a few nanometers in isolated structures (146). On the other hand, there 
are practical limitations to attain such resolution in densely-packed structures, mainly dictated by the proximity effect present in FEBID. A small halo around the main deposit exists in FEBID deposits due to precursor dissociation by secondary electrons reaching far distances beyond the primary impact point (26). The thickness of this halo (in the range of $10 \%$ of the thickness of the main deposit) rapidly falls with distance, and is in general not a problem for the functionality of isolated deposits. In the case of Co nanostructures, it has been shown that such halo structure in the vicinity of the main deposit at most modifies the magnetic coercive field (44). However, in densely-packed structures, a deposit grows in between the main structures that can be considerably thick, in the range of $50 \%$ of the thickness of the main deposit, as shown in Figure 10 (76). The route followed by De Teresa and Córdoba to fabricate arrays of densely-packed Co nanowires has been to grow in first place thickness-modulated deposits by fine control of the beam pitch (76). The pitch was as small as $30 \mathrm{~nm}$. Figure 10 illustrates the case of $40 \mathrm{~nm}$ pitch. One can notice in that figure a crest-valley periodic structure in agreement with such small beam pitch value. A subsequent soft $\mathrm{Ar}^{+}$plasma post-processing decreases the deposit thickness quite homogeneously along the full deposit, which finally leads to a set of isolated Co nanowires separated by distance corresponding to the pitch value. With that approach it has been possible to fabricate isolated nanowires every $40 \mathrm{~nm}$. 

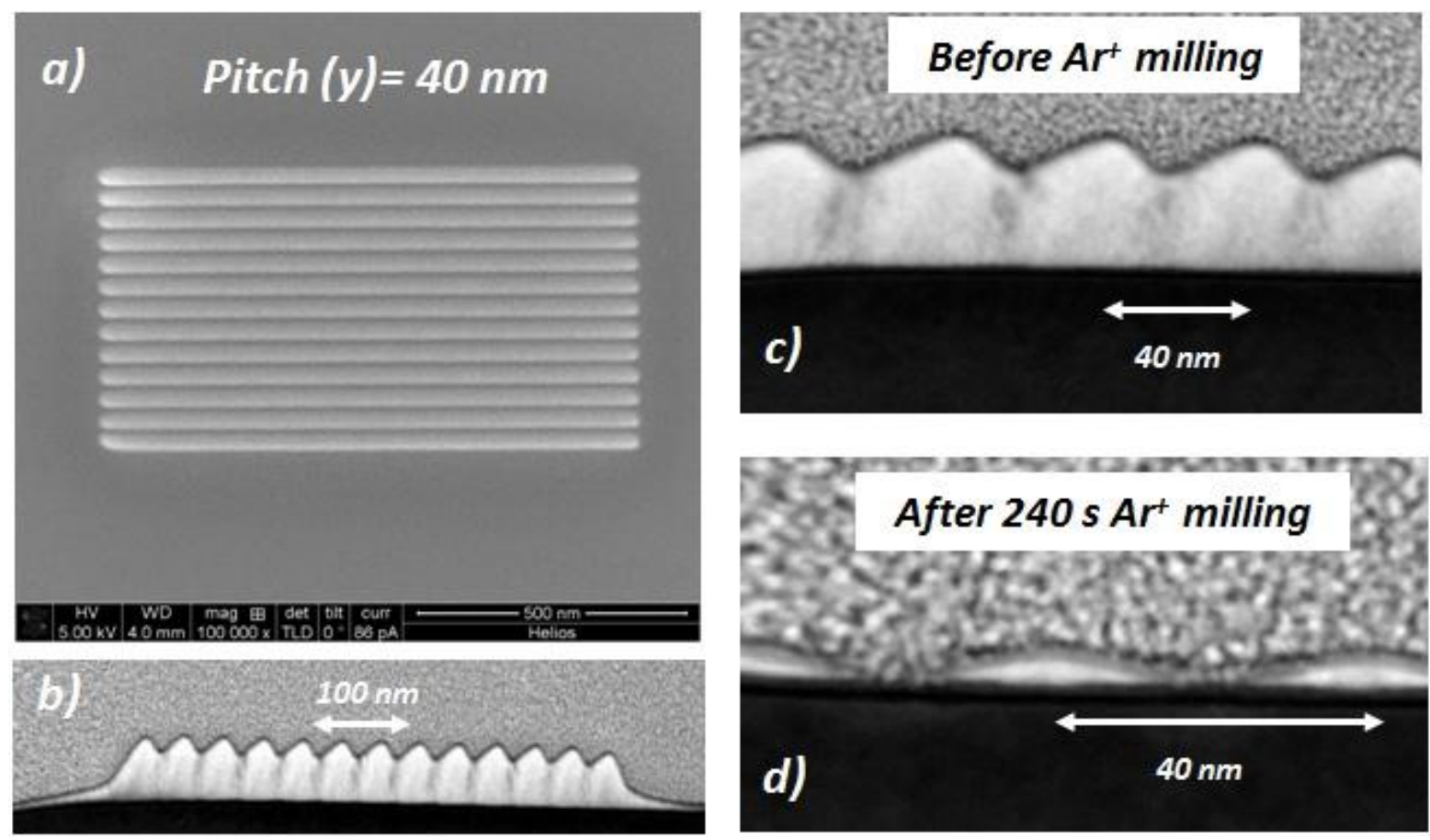

Figure 10. (a) Top-down image of an array of Co nanowires grown by FEBID with a pitch (center-to-center distance) of $40 \mathrm{~nm}$ (b) Cross-sectional SEM image of that array. Crosssectional TEM image of the same array before (c) and after $240 \mathrm{~s}$ of $\mathrm{Ar}^{+}$milling (d). Reprinted with permission from ACS Nano, 2014, 8 (4), pp 3788-3795. Copyright (2014) American Chemical.deteresa@unizar.es.

It is worth mentioning that Co nanowires have been grown by FIBID using a helium ion microscope (74). Although the lowest electrical resistivity reported in those nanowires (64 $\mu \Omega \mathrm{cm}$ ) is higher than in some Co FEBID nanowires (see section 2.2), the lateral resolution of isolated nanowires is very good, down to $10 \mathrm{~nm}$.

\subsection{Ion irradiation effects}

Nikulina et al. have found that a significant amount of material is deposited in between Co pillar structures (caused by halo effects), which totally modifies the magnetic coupling between them as well as their magnetization reversal mechanism (68). These authors have 


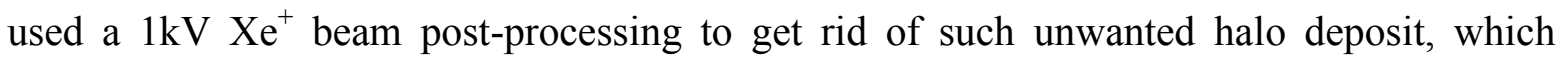
minimizes the magnetic coupling amongst the pillars, separated around $200 \mathrm{~nm}$ as displayed in Figure 11.

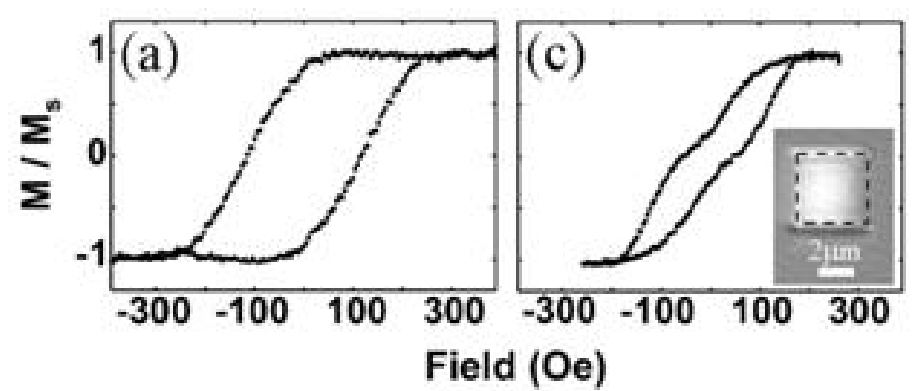

(b)

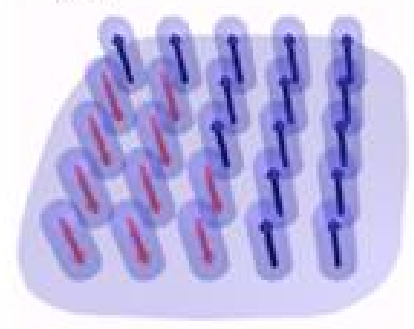

(d)

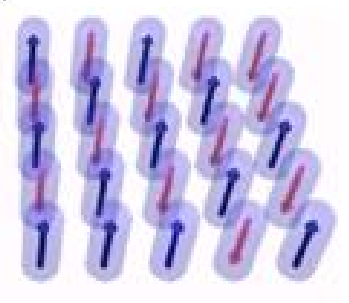

Figure 11. Out-of-plane MOKE hysteresis loops and schematic sketches of possible magnetization reversal states for 2-dimensional arrays of FEBID cobalt nanopillars: asdeposited structures, having the pillars connected with the cobalt halo (a), (b) and Xe ion exposed with a of dose $120 \mathrm{mC} / \mathrm{cm}^{2}$ (c), (d). The inset in (c) shows the optical image of the sample, and the dotted square defines the region of interest used for measuring the MOKE loops. Reprinted with permission from E. Nikulina, O. Idigoras, J. M. Porro, P. Vavassori, A. Chuvilin and A. Berger "Origin and control of magnetic exchange coupling in between focused electron beam deposited cobalt nanostructures", Appl. Phys. Lett. 103, 123112 (2013). Copyright 2013, AIP Publishing LLC.

Serrano-Ramón et al. have performed $30 \mathrm{kV} \mathrm{Ga}^{+}$irradiation on 2D Co nanowires, finding some important consequences $(72,73)$. Up to irradiation doses of $3 \times 10^{16}$ ions $/ \mathrm{cm}^{2}$, the coercive field for magnetization reversal increases due to two main effects (72). The first effect is a decrease in the magnetic volume of the parasitic halo around the nanowire, which 


\subsection{Three-dimensional Co nanostructures}

One of the distinct features of FEBID is its capability to grow 3D structures. So far, most of the work has been focused on the growth of out-of-plane Co nanowires $(30,34,36,66,68$, $81,88,90)$. The angle formed by the nanowire with the substrate can be controlled through the tilting angle of the substrate with respect to the electron beam direction (66). Co nanowires with shape of nano-spirals can be fabricated by scanning the beam in circular form $(30,66)$. Some images of 3D Co nanowires grown by FEBID are displayed in Figure 12. The magnetization reversal mechanism of such $3 \mathrm{D}$ nanowires has been characterized by means of MOKE measurements (66). Also, recent electron tomography-holography measurements of a 3D Co nanowire grown on a special sample holder have allowed the study of the spatially-resolved 3D magnetic state of the nanowire (90). Suspended 3D Co nanowires have been investigated by Vavassori et al. for application in remote magnetomechanical nanoactuation (92). 


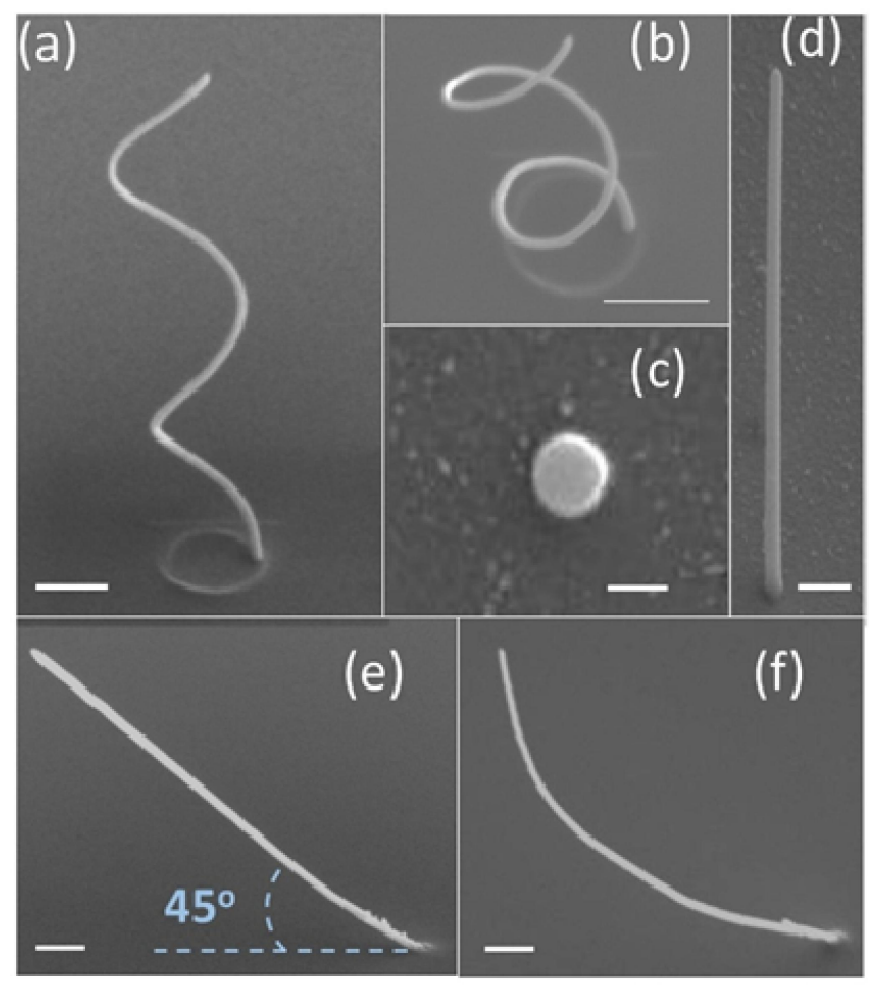

(g)
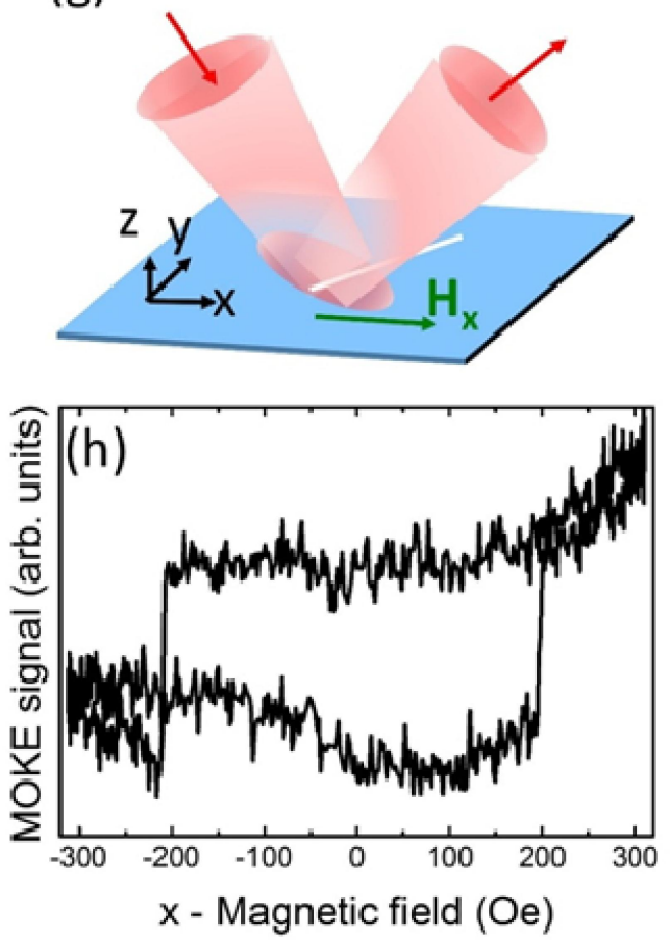

Figure 12. (a-f) SEM images of Cobalt 3D nanostructures grown by FEBID, including nano-spirals $(\mathrm{a}, \mathrm{b})$ and nanowires grown at different angles (c-f). (g,h) MOKE experiments in 3D nanowires on nanowires forming a $45^{\circ}$ angle with the substrate. Reprinted with permission from A. Fernández-Pacheco et al, Three dimensional magnetic nanowires grown by focused electron-beam induced deposition. Sci. Rep. 3, 1492 (2013). NPG.

FEBID is more adequate than other lithography techniques for cantilever functionalization given the difficulty of using photo- or electron-beam- resists on cantilevers. This was already realized on the pioneer work by Utke et al. to fabricate Co nanowires at the apex of cantilevers for Magnetic Force Microscopy (MFM) (36). More recently, magnetic Co deposits have been grown on soft cantilevers suitable for Ferromagnetic Resonance Force Microscopy (FMRFM) experiments $(61,79)$. In particular, the spherical geometry is the most suitable for that application given that it minimizes the magnetic hysteresis of the tip. In Figure 13, we show examples of nano-spheres grown by 
Sangiao, Casado and De Teresa in Zaragoza. The diameter of such nano-spheres ranges from $100 \mathrm{~nm}$ to $500 \mathrm{~nm}$ and their magnetic moment has been characterized by Mofakhami and De Loubens in CEA-Saclay to find that nano-spheres with diameter above $150 \mathrm{~nm}$ display magnetization values close to that of bulk $\mathrm{Co}, 1370 \mathrm{emu} / \mathrm{cm}^{3}$ (unpublished).

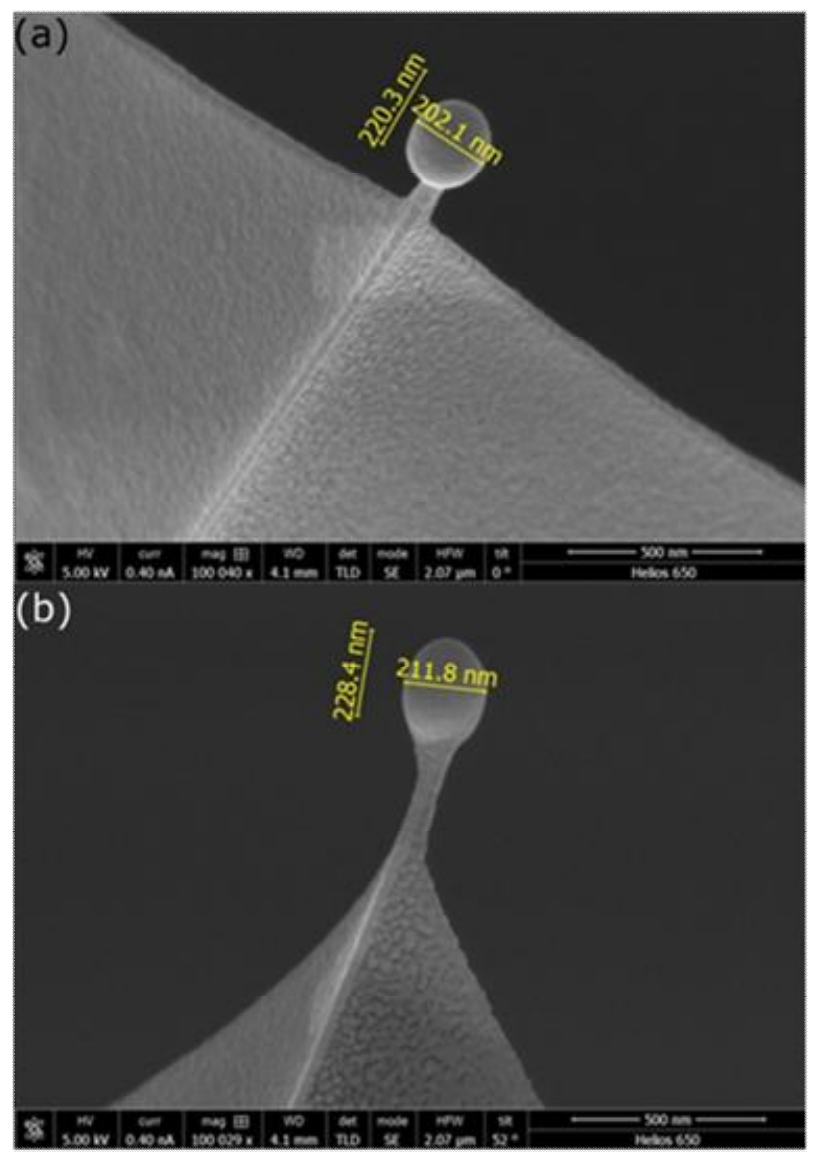

Figure 13. (a, b) Scanning electron micrographs of Co nanospheres of $200 \mathrm{~nm}$ in diameter grown at the tip of soft cantilevers used for Ferromagnetic Resonance Force Microscopy.

\section{Fe nanostructures by FEBID}

\subsection{Composition and microstructure}

The group of Furuya et al. investigated Fe deposits grown by FEBID using the $\mathrm{Fe}(\mathrm{CO})_{5}$ precursor along the period 2004 to 2007. They found that as-grown deposits consisted of a Fe:C nanocomposite with amorphous crystal structure which transformed into crystalline $\alpha$ - 
$\mathrm{Fe}$ and Fe-carbides phases after annealing processes at $600^{\circ} \mathrm{C},(103),(117),(118)$. Also, using mixtures of $\mathrm{H}_{2} \mathrm{O}$ and $\mathrm{Fe}(\mathrm{CO})_{5}$ precursors, these authors achieved the growth of crystalline $\mathrm{Fe}_{3} \mathrm{O}_{4}$ at room temperature (122). Additionally, by using mixtures of $\mathrm{Fe}\left(\mathrm{C}_{5} \mathrm{H}_{5}\right)_{2}$ and $\mathrm{Fe}(\mathrm{CO})_{5}$ precursors, the $\mathrm{Fe}$ content was controlled in the range $70 \%-30 \%(123)$. Furthermore, electron-beam-post-irradiation of Fe structures grown by FEBID was found to produce the formation of $\alpha-\mathrm{Fe}$ nanocrystals (104). In certain growth conditions (high precursor flux and long irradiation times), it was possible to observe the formation of $\alpha$-Fe nanocrystals at room temperature (124). The same effect of Fe-nanocrystal formation was later observed by Rodríguez et al. using the $\mathrm{Fe}_{2}(\mathrm{CO})_{9}$ precursor under growth conditions of high precursor flux and large beam current (144). Lavrijsen et al. used a mixture of $\mathrm{H}_{2} \mathrm{O}$ and $\mathrm{Fe}_{2}(\mathrm{CO})_{9}$ precursors to produce amorphous Fe deposits at room temperature, with varying Fe content in the range $50-80 \%(107)$. The growth of $3 \mathrm{D}$ nanopillars using the $\mathrm{Fe}(\mathrm{CO})_{5}$ precursor was found to be quite complex by Hochleitner et al. due to strong thermal effects (130). The nanopillars and the planar Fe deposits that show an amorphous or nanocrystalline structure, also present a 3-to-5-nm oxidized layer at the surface (134), (143), (144), (138). The best reported Fe content (80-85\%) in FEBID deposits grown in high-vacuum conditions at room temperature without annealing have been obtained by Gavagnin et al. using the $\mathrm{Fe}(\mathrm{CO})_{5}$ precursor (134) and by Rodríguez et al. using the $\mathrm{Fe}_{2}(\mathrm{CO})_{9}$ precursor (144).

\subsection{Magnetic and electrical properties}

Using the $\mathrm{Fe}_{3}(\mathrm{CO})_{12}$ precursor, Bruk et al. found that $\mathrm{Fe}$ deposits showed electrical resistivity values in the range $10^{4}-10^{9} \mu \Omega \mathrm{cm}(105)$. Lavrijsen et al. used a mixture of $\mathrm{H}_{2} \mathrm{O}$ and $\mathrm{Fe}_{2}(\mathrm{CO})_{9}$ precursors, giving rise to deposits with resistivity values in the range $10^{2}-10^{7}$ $\mu \Omega \mathrm{cm}$ (107) (142), to be compared with the value for pure Fe, of $10 \mu \Omega \mathrm{cm}$. A clear correlation is observed between the Fe content and the resistivity, as shown in Figure 14. 
Measurements of resistivity as a function of temperature indicate that the residual resistivity value $\left(\rho_{300 \mathrm{~K}} / \rho_{2 \mathrm{~K}}\right)$ approaches 1 for deposits with $70 \%$ Fe whereas it decreases to 0.05 for deposits with $56 \% \mathrm{Fe}$, a signature of semiconducting behavior (142). A giant value of the anomalous Hall effect was found in these samples, ascribed to the large contribution of skew scattering (142).

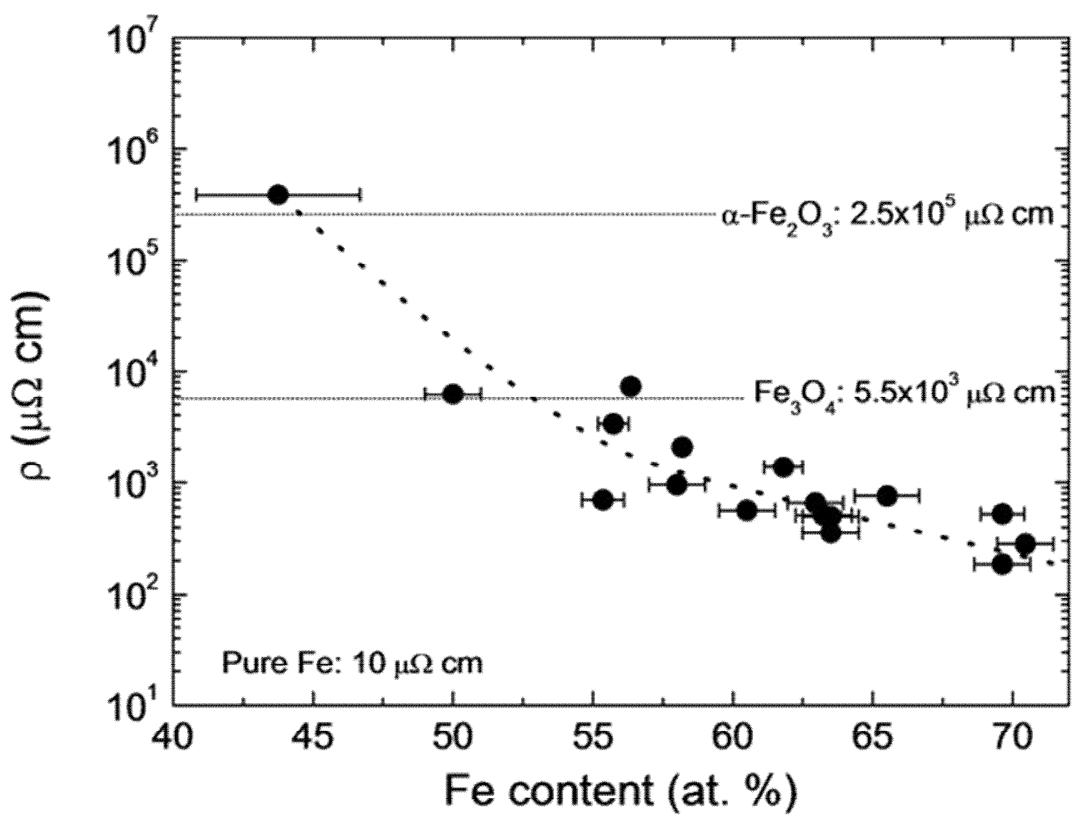

Figure 14. Room-temperature resistivity versus Fe content for Fe wires. The line is a guide to the eye. Reprinted with permission from R Lavrijsen et al 2011 Nanotechnology 22 025302. Copyright (2011), IOP. DOI: 10.1088/0957-4484/22/2/025302; deteresa@unizar.es.

In the following, we will describe the magnetic properties of Fe-based nanostructures grown by FEBID. Takeguchi et al. reported in as-grown and annealed nanorods the use of electron holography to infer magnetic induction values of $0.61 \mathrm{~T}$ and $0.45 \mathrm{~T}$ respectively (117). These are significant values, corresponding unequivocally to ferromagnetic response, but far from the bulk value of $\alpha-F e$, equal to $2.2 \mathrm{~T}$. In samples fabricated from mixtures of 
$\mathrm{Fe}\left(\mathrm{C}_{5} \mathrm{H}_{5}\right)_{2}$ and $\mathrm{Fe}(\mathrm{CO})_{5}$ precursors, where the $\mathrm{Fe}$ content was controlled in the range $70 \%$ $30 \%$, electron holography measurements gave magnetic induction values from $0.8 \mathrm{~T}$ down to $0.2 \mathrm{~T}$ (123). Lavrijsen et al. performed Kerr effect and magnetoresistance measurements demonstrating the ferromagnetic character of the Fe deposits grown with the mixture of $\mathrm{H}_{2} \mathrm{O}$ and $\mathrm{Fe}_{2}(\mathrm{CO})_{9}$ precursors (107) (142). From Hall-effect measurements on those samples, the authors estimated saturation magnetization values scaling with the deposit Fe content. Thus, the sample with $70 \%$ of $\mathrm{Fe}$ showed roughly $70 \%$ of Fe bulk saturation magnetization (107) (142). Using the $\mathrm{Fe}_{2}(\mathrm{CO})_{9}$ precursor, Franken et al. grew Fe pillars by FEBID on top of perpendicular magnetic domain-wall conduits which were able to pin moving domain walls through the stray field created by the pillar (143).

Gavagnin et al. fabricated small nano-magnets using the $\mathrm{Fe}(\mathrm{CO})_{5}$ precursor for application in nano-magnet logic, which were characterized by means of MFM measurements. They found that for fixed length and width, the coercive field was different for three different thicknesses. The same authors investigated by MFM the remanent magnetic state of Fe deposits with different geometrical forms (136). As shown in Figure 15 , good correspondence is found with the expected magnetic state when shape anisotropy is the main anisotropy source in such nanomagnets. 


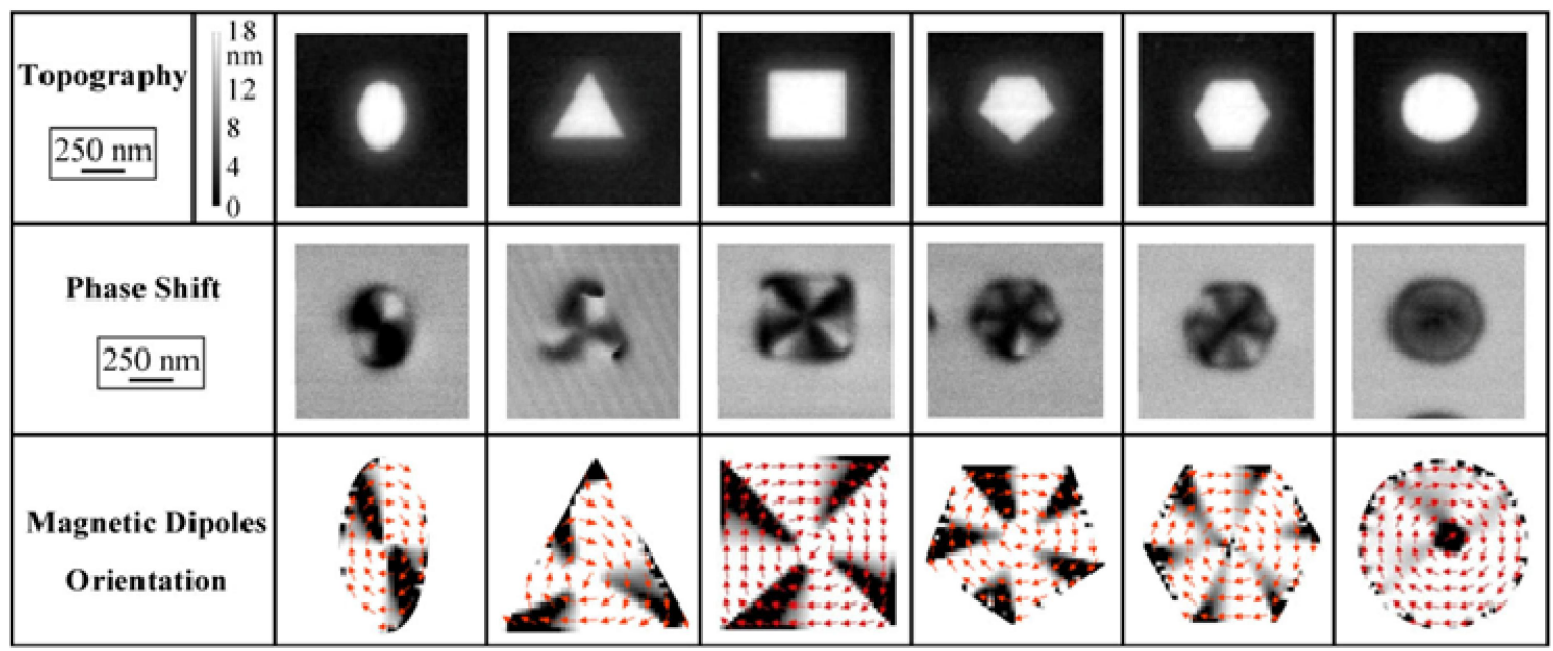

Figure 15. MFM investigation of the $\mathrm{Fe}$ nanostructures obtained by FEBID. The micromagnetic structure derived from simulations for each geometry is also represented. Reprinted with permission from M. Gavagnin, H. D. Wanzenboeck, D. Belic, M. M. Shawrav, A. Persson, K. Gunnarsson, P. Svedlindh, E. Bertagnolli "Magnetic force microscopy study of shape engineered FEBID iron nanostructures", Phys. Status Solidii A. 211, 368-374 (2014). Copyright 2014 WILEY-VCH Verlag GmbH \& Co. KGaA, Weinheim.

Rodríguez et al. have fabricated Fe nanowires (Fe content above $80 \%$ ) using the $\mathrm{Fe}_{2}(\mathrm{CO})_{9}$ precursor (144). These nanowires present lengths of $4.5 \mu \mathrm{m}$ and varying thickness (10 to $45 \mathrm{~nm}$ ) and width (50 to $500 \mathrm{~nm}$ ). A summary of the MOKE results in these samples is shown in Figure 16, where it can be noticed that the coercive field decreases with increasing width and thickness. Thus, the coercive field can be easily tuned by adjusting the dimensions of the nanowire. Micromagnetic simulations indicate that such dependence can be explained by magnetization reversal taking place via non-coherent magnetization rotation. The characteristic bell-shape of the deposits and the surface oxidation are also 
found to be relevant parameters in the exact value of the coercive field for each nanowire $(144)$.

a)

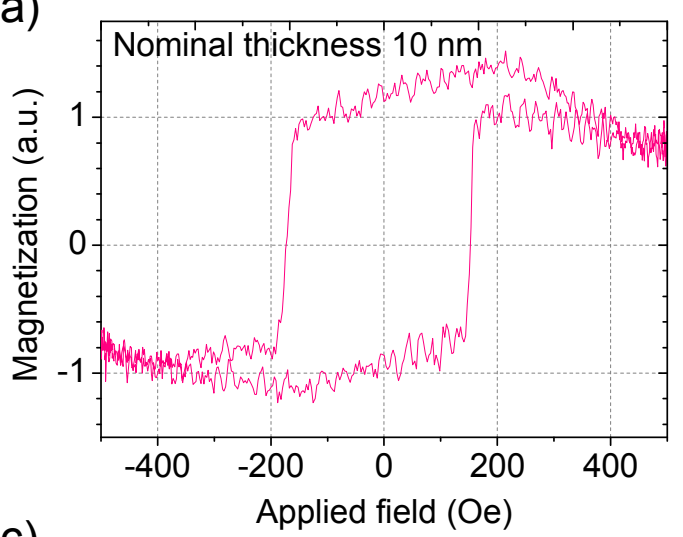

c)

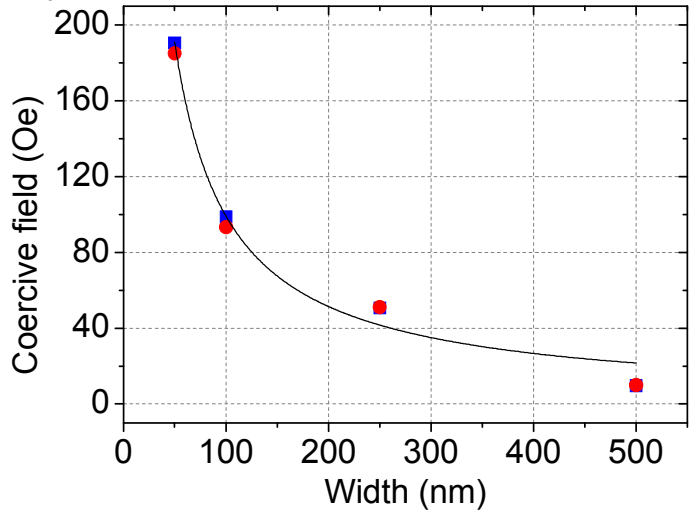

b)

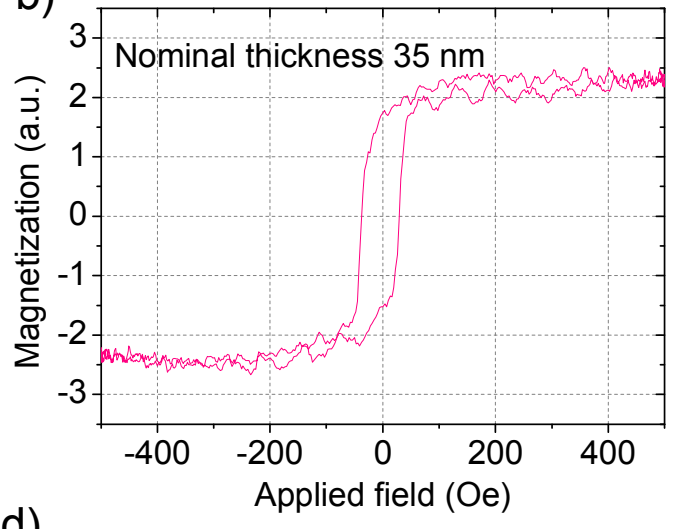

d)

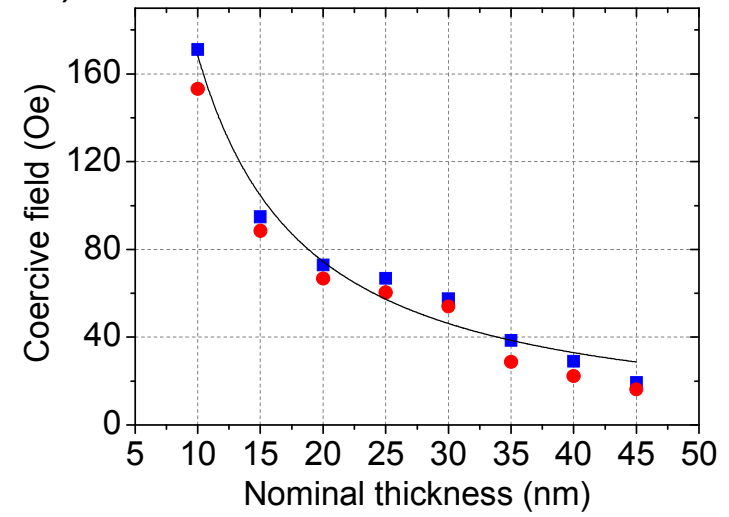

Figure 16. MOKE hysteresis loop of an Fe nanowire with $10 \mathrm{~nm}$ thickness (a) and $35 \mathrm{~nm}$ thickness (b). Dependence of the coercive field with width at fixed thickness of $25 \mathrm{~nm}$ (c) and with thickness at fixed width of $250 \mathrm{~nm}$ (d). Reproduced with permission from Rodriguez LA, Deen L, Cordoba R, Magen C, Snoeck E, Koopmans B, et al. "Influence of the shape and surface oxidation in the magnetization reversal of thin iron nanowires grown by focused electron beam induced deposition" Beilstein Journal of Nanotechnology 6, 1319$1331(2015)$.

\subsection{Fe deposits in ultra-high-vacuum conditions}

The group of H. Marbach et al. has investigated Fe deposition in UHV conditions using the $\mathrm{Fe}(\mathrm{CO})_{5}$ precursor. In 2008, Lukasczyk et al. reported the growth of Fe nanostructures with 
$95 \%$ of Fe content, which was attributed to the ultra-clean conditions of the chamber and the Si substrate surface (109). By working on perfectly-clean and less-clean Rh (110) surfaces, Lukasczyk et al. have revealed the importance of the surface to produce catalytic-driven precursor decomposition (131). The catalytic growth-rate enhancement under certain growth conditions using the $\mathrm{Fe}(\mathrm{CO})_{5}$ precursor had already been observed by Kunz and Meyer (101). Walz et al. have found that electron irradiation of $\mathrm{SiO}_{2}$ surfaces prior to gas dosing produces active $\mathrm{SiO}$ sites that decompose the $\mathrm{Fe}(\mathrm{CO})_{5}$ molecules without the need of electron-beam direct dissociation (147). After nucleation of the first Fe clusters, nanocrystal formation proceeds via auto-catalytic decomposition of the $\mathrm{Fe}(\mathrm{CO})_{5}$ precursor. This procedure has been coined Electron Beam Induced Surface Activation (EBISA) and the topic has been recently reviewed by H. Marbach (148). As displayed in Figure 17, Fe microwires prepared by EBISA show electrical resistivity of $88 \mu \Omega \mathrm{cm}$ at room temperature (132), still far from the bulk Fe value $(10 \mu \Omega \mathrm{cm})$ but lower than the value of $186 \mu \Omega \mathrm{cm}$ displayed by micro-wires with $70 \% \mathrm{Fe}$ content grown in high-vacuum conditions and studied by Córdoba et al. (142). From Hall resistivity measurements in the same EBISA samples, Porrati et al. (132) estimated a saturation magnetization of $1.47 \mathrm{~T}$, which is similar to the value found by Córdoba et al. (142). The tendency of Fe deposits to surface oxidation can be avoided by the growth of a protective capping layer, as carried out by Schimer et al. with a second titanium-oxide deposit (133). Fe deposits grown by EBISA have permitted fundamental studies related to the proximity effect (149) (150). In fact, using $\mathrm{TiO}_{2}$ substrates and the EBISA technique, Vollnhals et al. have fabricated Fe nanowires of width about $20 \mathrm{~nm}(151)$. 


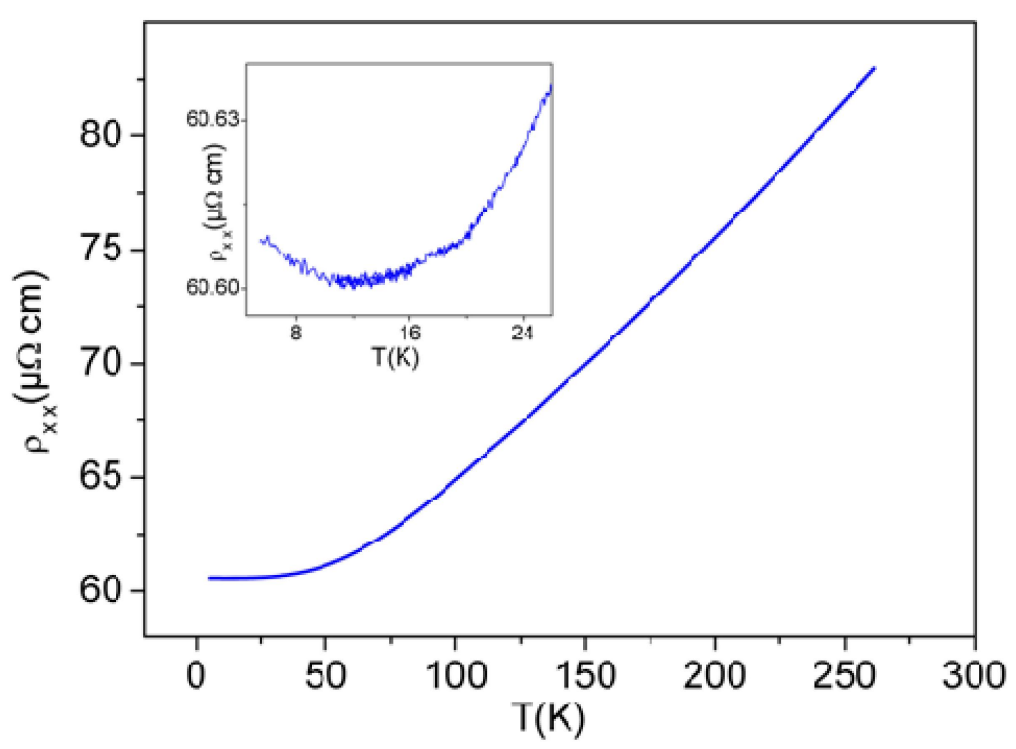

Figure 17. Temperature dependence of the longitudinal resistivity $\rho_{\mathrm{xx}}$ of Fe microwires grown by EBISA technique, showing that the behaviour is that of a metal. Below $12 \mathrm{~K}$ the resistivity slightly increases, see the inset. Reproduced with permission from F. Porrati, $R$. Sachser, M-M. Walz, F. Vollnhals, H-P. Steinrück, H. Marbach and M. Huth, "Magnetotransport properties of iron microwires fabricated by focused electron beam induced autocatalytic growth”, J. Phys. D: Appl. Phys. 44, 425001, (2011).

\section{Ni and alloyed nanostructures}

\subsection{Ni nanostructures}

Perentes et al. investigated the growth of $\mathrm{Ni}$ nanostructures using the $\mathrm{Ni}\left(\mathrm{PF}_{3}\right)_{4}$ and $\mathrm{Ni}\left(\mathrm{C}_{5} \mathrm{H}_{4} \mathrm{CH}_{3}\right)_{2}$ precursors (111). The maximum $\mathrm{Ni}$ content obtained was $40 \%$ and $10 \%$ respectively. The minimum electrical resistivity achieved was respectively $10^{3} \mu \Omega \mathrm{cm}$ and $10^{6} \mu \Omega \mathrm{cm}$, much larger than that of pure $\mathrm{Ni}, 6.9 \mu \Omega \mathrm{cm}$. These authors also tried simultaneous injection of molecular flows of oxygen and hydrogen with the Ni precursors, without improvement of the Ni content (111). More recently, Córdoba et al. have extended 


\subsection{Co and Fe alloys}

The main route to achieve the growth of Co and Fe alloys by FEBID has consisted of the simultaneous use of two precursors during growth plus subsequent annealing procedures. Following this route, Che et al. synthesized $\mathrm{L} 1_{0} \mathrm{Fe}-\mathrm{Pt}$ alloy nanorods at $600{ }^{\circ} \mathrm{C}$ that showed high magnetic induction values $(\approx 1.5 \mathrm{~T})$ as measured by electron holography (121). The same group used later a modified sequence of deposition and annealing procedures to achieve various Fe-Pt alloys (125). Porrati et al. obtained $\mathrm{L}_{0}$ Co-Pt alloys by using two simultaneous precursors plus a room-temperature post-electron-irradiation process (65). Interestingly, Dobrovolskiy et al. have carried out controlled post-processing with mesoscale lateral resolution, which permits to tune the coercive field locally (85). The same group has also fabricated Co-Si alloys by simultaneously injecting two precursors which relative flux can be controlled, producing alloys with tunable $\mathrm{Co} / \mathrm{Si}$ content and corresponding modulation in the electrical resistivity (69). Shawrav et al. have grown in a similar way Fe- 
Au nanoalloys (139). In general, this route is able to produce nano-crystalline alloys at room temperature but with a substantial amount of residual species, typically carbon.

Another strategy followed by Tanaka et al. was to synthesize iron silicide arrays of nano-rods or nano-triangles by using $\mathrm{Fe}(\mathrm{CO})_{5}$ precursor, $\mathrm{Si}(111)$ substrates, high substrate temperature and electron deposition in a TEM (152). Nano-rods as long as $100 \mathrm{~nm}$ and 10 $\mathrm{nm}$ in width were grown in this way (153). When the same authors used $\operatorname{Si}(110)$ substrates, beta-FeSi $i_{2}$ islands were formed instead (126).

On the other hand, Pérez-Roldán et al. have grown nano-pillars by FEBID using simultaneously $\mathrm{Co}_{2}(\mathrm{CO})_{8}$ and $\mathrm{Si}\left(\mathrm{OC}_{2} \mathrm{H}_{5}\right)_{4}$ precursors, finding that the growth of Co occurs at the outer part of the pillar (88). This forms a kind of Co magnetic tubule filled with nonmagnetic silicon oxide. The ferromagnetic properties are thus exclusively localized at the outer part of the structure as revealed by electron holography. Compositionallyinhomogeneous deposits at the nanoscale had been previously observed in FIBID deposits using two precursors, $\mathrm{W}(\mathrm{CO})_{6}$ and $\mathrm{C}_{10} \mathrm{H}_{8}$ (154). Precursor competition with relevant kinetical processes upon certain growth conditions is the underlying reason for that intriguing behavior, which could be of general occurrence in co-deposition.

Recently, Porrati et al. have used a single bimetallic precursor, $\mathrm{HFeCo}_{3}(\mathrm{CO})_{12}$, to directly grow an alloy (110). The composition of the deposits is roughly Co:Fe:C:O= 60\%:20\%:10\%:10\%. The lowest room-temperature resistivity found is $43 \mu \Omega \mathrm{cm}$ and the maximum magnetic induction is estimated to be $\approx 1.6 \mathrm{~T}$. TEM measurements indicate that the deposits consist of a bcc Co-Fe phase mixed with a $\mathrm{FeCo}_{2} \mathrm{O}_{4}$ spinel oxide phase with nanograins about $5 \mathrm{~nm}$.

It is pertinent to mention that some magnetic alloys grown by FIBID have been reported. Thus, $\mathrm{Xu}$ et al. grew $\mathrm{FePt}$ and $\mathrm{CoPt}$ micro-particles using two precursors simultaneously and performing an annealing process at $600^{\circ} \mathrm{C}$ to crystallize the particles 
(113). Pogoryelov and Suzuki used three precursors simultaneously to grow FeCoPt ternaryalloy micro-particles which showed different magnetic properties before and after annealing at $600^{\circ} \mathrm{C}(141)$.

\section{Applications of magnetic nanostructures by FEBID}

In the following subsections, the most important applications reported so far for magnetic nanostructures grown by FEBID will be described.

\subsection{Magnetic dots for magnetic storage and catalytic growth}

Dots grown by FEBID can have very small dimensions, in the nanometer range, as already demonstrated using $\mathrm{Pt}$ precursor (155). However, the requirements of current magneticrecording technology are very stringent $(2,156)$. For example, the magnetic anisotropy of the recording units should be large enough to retain the information for long periods of time. The present limitations in the chemistry of precursors and the difficulties in tailoring the crystal structure make quite improbable the use of magnetic dots grown by FEBID for this application. Nevertheless, the potential of beam-induced deposition for growing magnetic dots with small periodicity has been demonstrated (32) (33) (37) (38) (116) (120) and an interesting application of this type of structures in catalysis has been demonstrated by Ervin and Nichols (100). These authors used Co deposits grown with different doses to catalyze the growth of carbon nanotubes (CNTs). They found that at low doses no growth of CNTs occurred, whereas at intermediate and high doses single-wall and multi-wall CNTs were grown respectively. These differences were ascribed to the Co nanoparticle size variation $(100)$. 


\subsection{Growth of MFM and FMRFM tips}

For applications in high-resolution Atomic Force Microscopy, carbon-based tips grown by FEBID have been proposed (157). The high aspect ratio of the apex achievable in such tips made them to be coined supertips. For the study of magnetic samples, MFM tips are usually fabricated by evaporating a magnetic layer on an AFM cantilever (158). This implies that the magnetic interaction between tip and sample is somehow delocalized, which can lead to a loss of sensitivity and lateral resolution. Utke et al. challenged the growth of Co supertips for MFM studies (35) (36). As shown in Figure 18, the advantage of FEBID is the precise growth of the magnetic tip at the apex of a cantilever with controlled tip dimensions. Such tips were used to image the magnetic bits of a hard disk, reaching magnetic imaging resolution of $40 \mathrm{~nm}$ (36). Subsequent work by Belova et al. has improved the resolution of Co magnetic tips down to $10 \mathrm{~nm}$ (61). On the other hand, Gavagnin et al. have grown Fe tips using FEBID for MFM where the importance of the tilt angle of the magnetic tip with respect to the scanned sample has been revealed (138). 


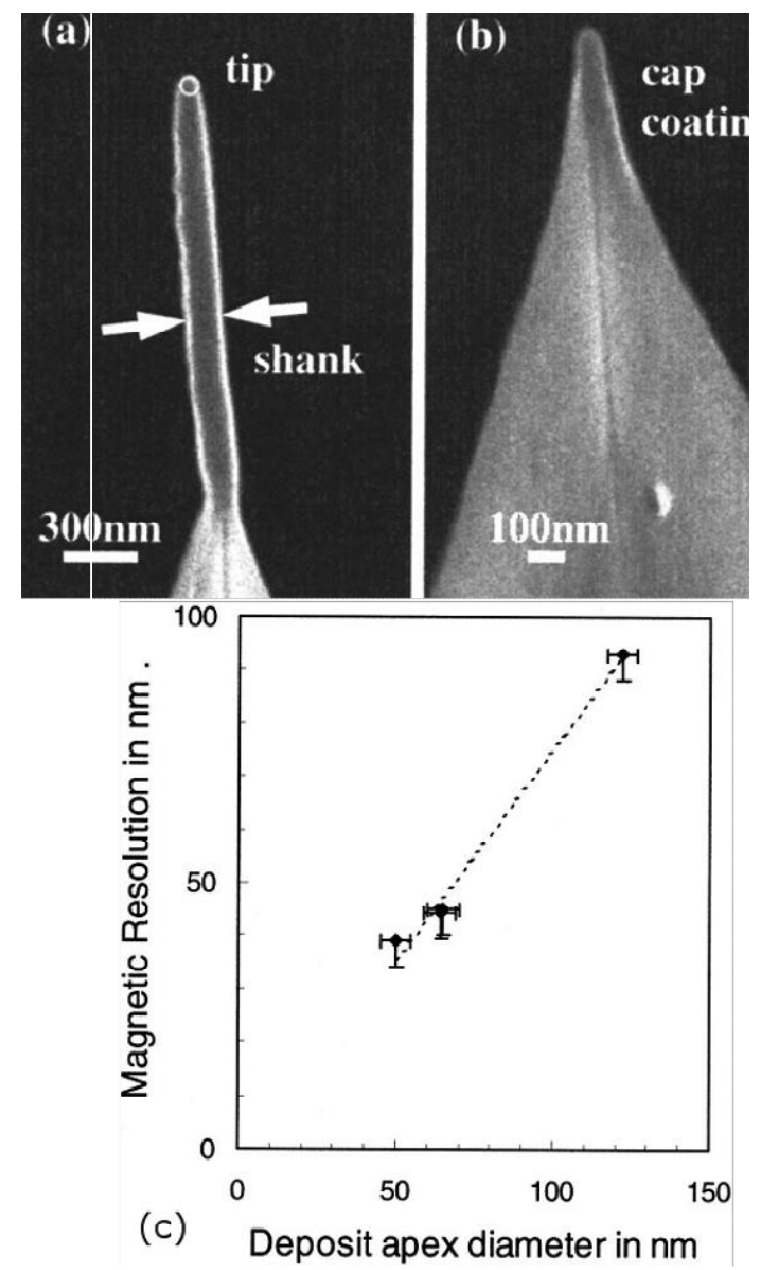

Figure 18. Scanning electron micrographs of typical FEB deposits. A high-aspect-ratio magnetic tip on top of a pyramidal Si tip is shown in (a). Deposition parameters are $133 \mathrm{pA}$ at $25 \mathrm{kV}$ during $2 \mathrm{~min}$. The tip apex diameter is $72 \mathrm{~nm}$, the shank diameter $160 \mathrm{~nm}$, and the tip length is $1.7 \mathrm{~mm}$. Magnetic cap coatings (b) are deposited at $100 \mathrm{pA}, 25 \mathrm{kV}$, and $5 \mathrm{~s}$ resulting in $50 \mathrm{~nm}$ of apex diameter. (c) MFM resolution of several FEB deposits measured under ambient conditions with the lift-retrace tapping mode. The magnetic resolution corresponds to the smallest resolved magnetic transition. The resolution error is assumed as one half of the difference of the smallest resolved transition and the adjacent nonresolved transition. The dashed interpolated line has a slope of 0.8. Reprinted with permission from [I. Utke et al., Applied Physics Letters 80, 4792 (2002)]. Copyright [2002], AIP Publishing $L L C$. 
Another interesting application of magnetic deposits by FEBID in the field of scanning microscopies has been recently unveiled. As introduced in section 2.5, FMRFM experiments are based on magnetic resonance force microscopy, where the magnetic resonance of a magnetic sample is sensitively detected through the magnetic force exerted on a cantilever equipped with a small magnetic tip (159). A soft cantilever is commonly used with a magnetic nanosphere glued at the apex (160). The spatial resolution of the technique is directly linked to the size of the nanosphere. Gluing a sub-micron particle to the apex of a cantilever tip is a painstaking work that can be substituted by directly growing it by FEBID. Using FEBID Co nanoparticles, very successful FMRFM experiments have been performed so far (161) (162) (163) (164) (165) (166) .

\subsection{Nano-Hall sensors for bead detection}

In a Hall sensor, the voltage output changes as a function of magnetic field due to the Hall effect, which generates a transverse voltage perpendicular to the passing current. The voltage output is governed by the properties of the material and the existing external magnetic field. In general, the Hall sensor is based on either a semiconductor material with a linear response as a function of the external magnetic field due to the ordinary Hall effect or a magnetic material with an additional contribution due to the anomalous Hall effect (167). Hall sensors with high spatial resolution are interesting in diverse applications: in biosensing for the detection of biological moieties conjugated to magnetic nanoparticles (13), in scanning Hall microscopy (168), in nano-magnetometry (169), in magnetic logic applications (170), etc. Boero et al. reported that sub-micrometric Co Hall sensors can be grown by FEBID with good sensitivity (40). Further work demonstrated the great potential of such Co Hall sensors, with minimum magnetic flux detectable in the range of $10^{-6} \mathrm{x} \Phi_{0}$, where $\Phi_{0}$ is the quantum of flux (48) (60). This value is very competitive compared to other 


\subsection{Nanowires in 2D and 3D for domain-wall manipulation}

The concept of domain-wall conduit was introduced in 2002 by Cowburn et al. to illustrate the unperturbed propagation of magnetic domain walls inside a magnetic material (171). Such behavior implies that the magnetic field required to displace a domain wall within the nanowire (the propagation field) is lower than the magnetic field required to create new domain walls (the nucleation field). This effect can be applied for applications in magnetic logic (9) as well as in racetrack memories (8). Fernández-Pacheco et al. demonstrated that 2D Co nanowires grown by FEBID sustain unperturbed propagation of domain walls (43). Figure 19 illustrates such behavior. L-shaped nanowires were grown in order to measure the nucleation and propagation fields of domain walls in this material. The results indicated that, in the range of nanowire dimensions studied, the propagation field is lower than the nucleation field. The most appropriate dimensions for optimized domain-wall conduit behavior were later determined by Rodríguez et al. using Lorentz microscopy (71). These authors concluded that such dimensions were related to the crossover between the formation of transverse and vortex domain walls. 

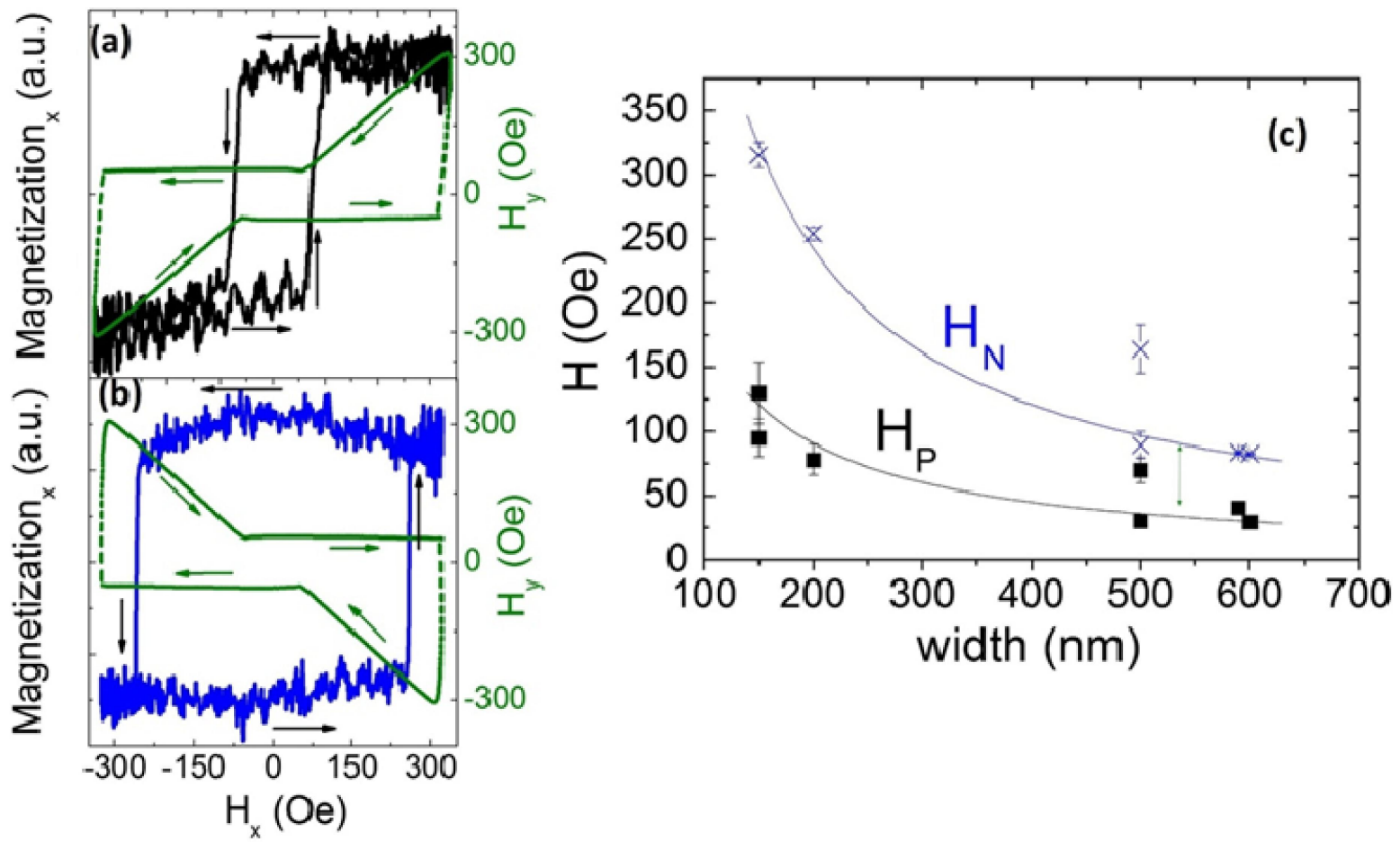

Figure 19. (a,b) MOKE hysteresis loops (black and red) and field sequences used (green) in L-shaped nanowires grown by FEBID, showing a lower switching field for propagation (a) than for nucleation (b). (c) Nucleation and propagation field as a function of width, proving a good domain wall conduit for the wires. Reprinted with permission from FernándezPacheco et al. Domain wall conduit behavior in cobalt nanowires grown by focused electron beam induced deposition. Applied Physics Letters. 2009;94(19):192509. Copyright 2009 AIP Publishing LLC.

Additionally, Serrano-Ramón et al. found that an improvement in the domain-wallconduit behavior of 2D Co nanowires grown by FEBID was achievable by high-voltage global $\mathrm{Ga}^{+}$irradiation (72), as mentioned in section 2.4. This was linked to the structural and micro-structural changes produced by the highly-energetic irradiation. Moreover, local $\mathrm{Ga}^{+}$ irradiation was found to pin domain walls efficiently at well-localized areas, as directly observed by means of scanning transmission x-ray microscopy (73). 
The domain-wall-conduit behavior has not been proved in FEBID Fe nanowires so far. Micromagnetic simulations performed by Rodríguez et al. in 2D nanowires indicate that the magnetization reversal is quite complex and not via simple transverse or vortex wall nucleation and propagation (144). The domain-wall-conduit behavior in 3D magnetic nanowires grown by FEBID is still an open question too, although Fernández-Pacheco et al. suggested that it could be the case in 3D Co nanowires (66).

Another application has been demonstrated by Franken et al., who have used Fe nanopillars grown by FEBID on top of perpendicular domain-wall conduits to pin domain walls in a controllable way (143). The positive or negative stray field produced by the Fe nanopillars on the magnetic domain-wall conduit is used to stop or let pass the corresponding domain wall under the pillar.

\subsection{Spintronics and nanomagnetism}

Spintronics relies on the spin degree of freedom of the electron to build electronic devices (172) (173). Spintronics is currently at the basis of many types of memories and sensing schemes (5) (7) (8) (174). One of the most successful devices is a magnetic tunnel junction, consisting of two magnetic layers separated by an insulating layer. The current proceeds via spin-polarized tunneling and gives rise to large magnetoresistance ratios beyond $500 \%$ at room temperature (175). This has been achieved through complex engineering of the thickness, composition and crystallographic structure of all the layers forming the magnetoresistive stack. Constanzi et al. have challenged the growth of magnetic tunnel junctions using Co electrodes and $\mathrm{SiO}_{2}$ barrier, all grown by FEBID (75). Unfortunately, the obtained $0.5 \%$ magnetoresistive ratio, comparable to the anisotropic magnetoresistance value of Co, $0.8 \%(42)$, is three orders of magnitude below the state of the art, and has little chances of applicability without further development. One of the potential issues in the 
grown device is the quality and nature of the barrier, which is known to play a central role in magnetic tunnel junctions (176). It is worth mentioning that Sangiao et al. have measured a high spin polarization (40\%) for Co grown by FEBID in Andreev reflection measurements (59). This value is close to that measured for Co grown by sputtering (177). This means that, in principle, Co grown by FEBID can be used efficiently in spintronic devices as an active element. It is also worth mentioning the work by Fernández-Pacheco et al. regarding the fabrication of Co nanoconstrictions grown by FEBID in a single step (93). The good correlation between the magnetoresistive behavior of such nanoconstrictions and their magnetic state probed by scanning transmission $\mathrm{x}$-ray microscopy is indicative of the good functionality of this material down to the nanoscale (93).

Other routes have been followed by the group of M. Huth to apply FEBID materials in the field of Spintronics and Nanomagnetism. Pohlit et al. have grown artificial square spin ice structures based on Co nanowires grown by FEBID (89) (91). Artificial spin ice structures, characterized by geometrical frustration, are being studied for their exotic physical behavior and are potential candidates for memory devices (178). The results by Pohlit et al. point towards magnetization reversal statistically following different paths most likely driven by thermal perturbations (89). The differences between the magnetic behavior of isolated Co nanoislands grown by FEBID and the cluster formed by several interacting Co nanoislands have been highlighted by the same authors (91). On the other hand, Porrati et al. have fabricated Co nanopillars embedded in a Pt-C nano-granular matrix to achieve magnetoresistive effects (81). All the constitutents of the device have been grown by FEBID. The value of the magnetoresistive effect measured at $4 \mathrm{~K}$ is low, below $6 \%$. Besides, Lara et al. have fabricated circular Co disks by FEBID, designing holes by FIB in order to investigate their magnetization reversal through metastable states with half antivortices (80). The device is shown in Figure 20. The pinning landscape provided by the 
holes guide the magnetization reversal. The authors argue that the finding is relevant for the development of multi-hole spintronic and magnetic memory devices.

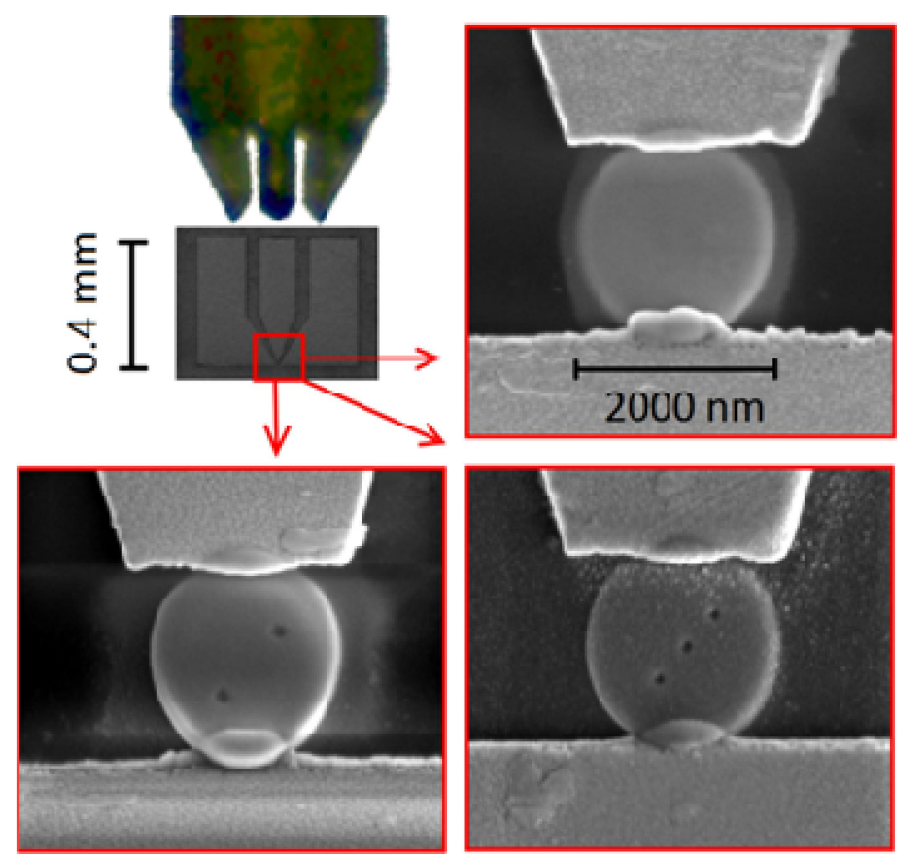

Figure 20. The top left panel shows an optical image of the high frequency probe and the gold contacts to which it is attached. The other three panels show SEM images of the Co dots deposited by FEBID between the gold contacts. Three cases are shown: without nanoholes, with two nanoholes, and with three nanoholes. Reprinted with permission from A. Lara et al., Applied Physiscs Letters 105, 182402 (2014). Copyright [2014], AIP Publishing LLC.

The recent use of 3D Co nanowires for magnetomechanical actuation is another promising route of work. The authors foresee applications in fields such as nanobiomechanics, nano-optics and nano-transport (93).

\subsection{Nano-magnetic logic}

Highly-integrated nanomagnets with dipolar coupling have been proposed for application in logic computing, the field being coined nanomagnet logic (179). Different logic gates have 
been demonstrated using materials such as Permalloy or $\mathrm{Co} / \mathrm{Pt}$ films grown by sputtering (180). Gavagnin et al. have used 2D Fe nanomagnets grown by FEBID to build demonstrative logic gates (134). As an example of this, a NAND/NOR logic gate is shown in Figure 21. The same group later showed the capability of FEBID to fabricate 3D logic gates using again Fe deposits (138).
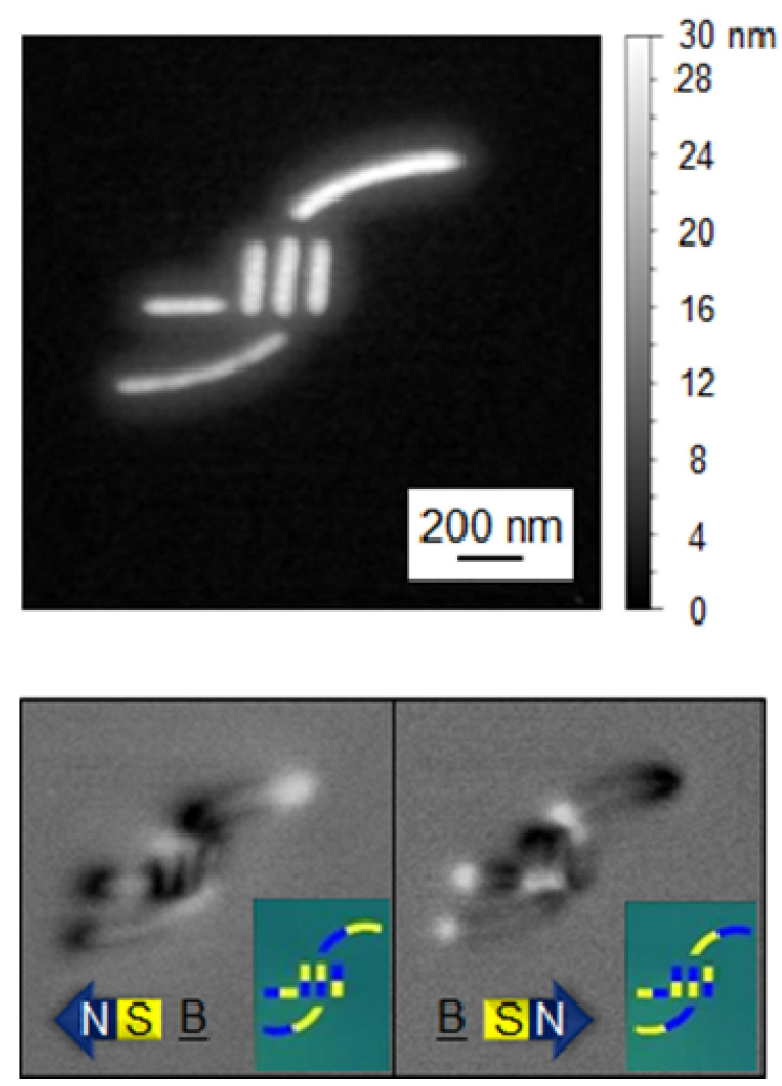

Figure 21. Topography (top) and phase shift (bottom) MFM images of the NAND/NOR gates fabricated by the merging of NWs. The phase shift images evidence the magnetic reversal of the gates by applying an external magneticfield in opposite directions (arrows directions), whereas the inlays in panel a, show the magnetic dipole orientations where blue and yellow represent north and south poles, respectively. Reprinted with permission from $M$. Gavagnin, H. D. Wanzenboeck, D. Belic and E. Bertagnolli, "Synthesis of individually tuned nanomagnets for nanomagnet logic by direct write focused electron beam induced deposition”, ACS Nano, 7, 777-784, (2013). Copyright 2012 American Chemical Society. 


\subsection{Combination of magnetic deposits with superconductors}

The group in Zaragoza demonstrated for the first time functional devices combining magnetic nanostructures grown by FEBID and superconducting nanostructures grown by FIBID (59) (58). The device, shown in Figure 22, consists of a nanocontact between the magnetic Co FEBID deposit and the superconductive W FIBID deposit. Such nanocontacts have allowed the extraction of important material parameters such as the spin polarization of the magnetic material and the superconducting gap (59). The value of the superconducting gap extracted from these experiments is in agreement with direct scanning tunneling microscopy experiments, which stresses the capability of preparing clean nanocontacts by FEBID/FIBID techniques with a single (or very few) conduction channel (181). Subsequent experiments in nanocontacts with worse definition or cleanliness gave rise to multi-channel transport (83). In fact, the experiments are difficult and, for example, the growth order is critical. If the FIBID superconducting deposit is grown after the magnetic one, the use of ions can degrade the magnetic properties of the nanocontact (182). 

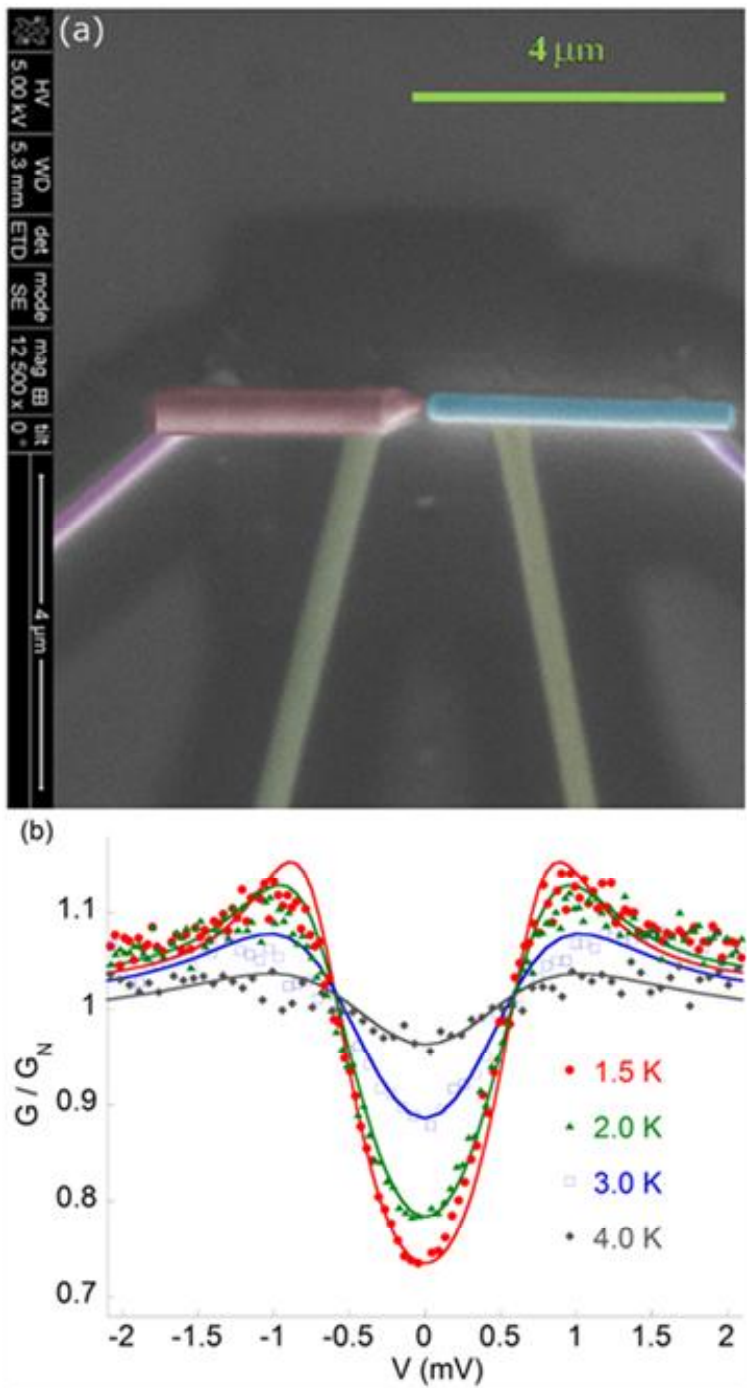

Figure 22. (a) Artificially coloured scanning electron micrograph of a $\mathrm{Co}-\mathrm{W}$ nanocontact created for current-in-plane Andreev Reflection measurements. (b) Temperature dependence of the normalized differential conductance of a $\mathrm{Co}-\mathrm{W}$ nanocontact as a function of the applied voltage. Solid lines are fits to the extended BTK model. Reprinted from Solid State Communications vol. 151, S. Sangiao et al., Ferromagnet-superconductor nanocontacts grown by focused electron/ion beam techniques for current-in-plane Andreev Reflection measurements, 37-41, Copyright (2011), with permission from Elsevier.

In another application followed by the group of M. Huth, arrays of Co stripes have been grown by FEBID on superconductive $\mathrm{Nb}$ films to create uniaxial pinning potentials for 
the movement of the vortex lattice (115) (47). Transport measurements in the superconductor confirm the expectation of an anisotropic behavior induced by the uniaxial pinning (47) as well as steps ascribed to matching effects between the Co line periodicity and the vortex lattice periodicity (51).

\section{Summary and outlook}

In the previous sections, the state-of-the-art usage of FEBID for the growth of magnetic nanostructures has been described. As a brief summary, since 2009 there is a revived interest in the growth of magnetic nanostructures by FEBID. In the following, our view on the expected evolution of the topic will be given. We focus on the main aspects involved in the topic, first on the growth, later on the applications themselves:

Regarding the growth, these are our views:

-New precursors for magnetic deposits: As shown in Table 1, the available precursors for growth of magnetic materials by FEBID are scarce. Recently, Porrati et al. introduced a heteronuclear precursor containing Fe and Co atoms (110). The total amount of metal content $(\mathrm{Fe}+\mathrm{Co})$ in the grown deposits was $80 \%$. New developments in precursor chemistry for the growth of alloyed magnetic materials are expected. In particular, the incorporation of rare-earth atoms in such precursors could be advantageous in certain applications in magnetism. In general, one of the limitations in the use of FEBID compared to other growth techniques such as sputtering is the lack of fine control in the final composition of the grown material.

-New strategies for purification of deposits: Although a high metal content (above $80 \%$ ) can be currently achieved in magnetic deposits grown at room temperature using Cobased and Fe-based carbonyl precursors, in some applications metal values close to $100 \%$ may be necessary. This is why purification methods such as those recently developed for 
magnetic materials are desired (84). In fact, such strategies should be easy to implement for broad dissemination.

-Growth of alloys by co-deposition: As described in section 4, very little work has been performed towards the growth of alloys by co-deposition. In some cases, the achievement of the searched crystallographic phase calls for high-temperature annealing processes. New magnetic alloys are expected to be grown by FEBID in the coming years to enlarge its applicability.

-Multi-layer deposition: For some magnetic devices like magnetic tunnel junctions, a stack of several materials should be grown. FEBID is well-suited for sequential deposition of materials and one can expect new strategies in this direction. The combination of magnetic materials with other functional materials (superconductive, optically-active, insulating, etc.) seems attractive to explore beyond the few existing examples discussed in section 5 .

-Combination of FEBID with other growth or lithography techniques: FEBID technique has been combined with Atomic Layer Deposition (ALD) for the growth of pure Pt nanostructures (183) (184) (185). Finding compatible FEBID-ALD processes for the growth of pure magnetic nanostructures would be an exciting new route. FEBID has been combined with FEBIE (Focused Electron Beam Induced Etching) to create $\mathrm{CoF}_{3}$ material (77), which is known to be an antiferromagnetic material. This could potentially give rise to $\mathrm{Co} / \mathrm{CoF}_{3}$ exchange-biased bilayers, with application in magnetic sensing.

-Use of FIBID: The composition and lateral resolution of Co deposits obtained by Wu et al. using the Helium Ion Microscope (HIM) are very promising (74). Although, in general, the use of ions on magnetic materials degrades their properties, in this case, the exhibited properties are of high quality. Further work using the HIM (or other ion sources) for the growth of magnetic materials would be fantastic. 
-Use of multi-electron-beam deposition: Another limitation of FEBID, the low growth rate, could be overcome by the use of multi-electron-beam deposition (186). Although such technology is still under development, its application for the fast growth of magnetic arrays would be welcome.

-FEBID on liquid environment: Some work exists on the use of liquid-phase electron-beam-induced deposition for $\mathrm{Pt}, \mathrm{Cu}$ and $\mathrm{Ag}$ (187) (188). In this case, the precursor is adsorbed on the substrate in liquid phase and a focused electron beam from an environmental SEM allows precursor decomposition into pure nanostructures. This strategy has not been used for the growth of magnetic materials yet.

-Catalytic growth: As described in section 5.1, the growth of CNTs on Co dots grown by FEBID has been achieved, underlining the potential of the technique for catalytic growth (100). On the other hand, various experiments have been developed regarding catalytic effects in FEBID itself (131). Further investigations in those directions can be envisaged, with importance in the fields of surface science and self-assembly.

-Use of non-standard substrates: One of the advantages of FEBID is the freedom in the choice of substrate. The work by Peinado et al. has demonstrated that FEBID can be achieved on unconventional substrates such as flexible and transparent polycarbonate ones (87). Given that some applications such as stretchable magnetoelectronics are very promising (186), further work regarding the growth of magnetic nanostructures on unconventional substrates is expected.

Regarding applications, these are our views:

-Magnetic storage: The present magnetic storage density, beyond $1 \mathrm{Tbit} / \mathrm{inch}^{2}$, and the stringent requirements of the hard disk components make difficult the change towards new magnetic storage strategies (189). However, the use of concepts for 3D magnetic storage is in vogue given the potentially-high storage density achievable $(8,190)$. As FEBID 
is well-suited for 3D growth, the development of 3D magnetic nanowires by FEBID (66) could be interesting in contexts like the racetrack memory (8). Given that 2D Co nanowires grown by FEBID display domain-wall conduit (43), 3D Co nanowires could also exhibit such a property.

-Domain-wall and logic: The use of magnetic domain walls for 2D logic concepts was introduced a few years ago using Permalloy nanostructures (9). Magnetic materials grown by FEBID, displaying domain-wall conduit (43), are appropriate for this application. On the other hand, Permalloy and $\mathrm{Co} / \mathrm{Pt}$ nanomagnets have been also used for the development of nanomagnet logic concepts (180). 2D and 3D logic gates grown by FEBID have been demonstrated (134) (138), but the present throughput is too low for cost-effective device production. One should also consider that, despite domain-wall and nanomagnet logic concepts are beautiful, the great improvements achieved in Si-based logic makes improbable the use of magnetic domain walls in next-generation logic devices.

-Scanning Probe Microscopy (SPM) tips: The difficulties to functionalize SPM tips with standard growth and lithography techniques make FEBID a competitive technique in this application. Although some proof-of-concept examples have been shown for MFM, as described in section 5.2, real applications are almost inexistent. However, we foresee strong potential for topics such as quantitative MFM or high-resolution MFM. The results achieved so far in FMRFM using Co deposits grown by Belova et al. indicate that FEBID is indeed very useful in this application (163).

-Magnetic prototyping: FEBID produces nanopatterned magnets with high resolution and shapes, and on non-standard substrates, which can be very difficult or impossible to obtain with other growth and lithography techniques. This is very useful for magnetic prototyping so that new magnetic states can be investigated with advanced local magnetic characterization techniques (90). 
-Vortex lattice pinning: Physical phenomena in superconductors is very rich and with important technological implications. One of the holy grails in this field is the improvement of the critical current by means of hampering the motion of the vortex lattice in type-II superconductors. The use of magnetic nanostructures grown by FEBID for vortex pinning is a clean and effective process that permits the study of important effects related to vortex physics (51). Further studies in this direction will improve the understanding of the phenomena for adequate design of the vortex-pinning landscape in high- $\mathrm{T}_{\mathrm{C}}$ superconductors used in real applications.

-Remote magnetomechanical actuation: Nano-actuators normally use electrical contacts to convert electrical stimuli into mechanical motion. However, remote operation of nano-actuators by magnetic fields, avoiding the need of electrical contacts, has been recently demonstrated (93). The nano-actuators have been fabricated using Co nanowires grown by FEBID. This will surely inspire new devices based on this strategy.

Summarizing, the FEBID technique finds various applications in the fields of nanomagnetism and spintronics, mainly on some specific situations where this technique has competitive advantages with respect to the use of standard thin-film growth plus nanolithography. We foresee that FEBID will become better known in the coming years and will be used on the same foot as other growth and lithography techniques.

Acknowledgements. We are very grateful to many scientific collaborators in this field along the last six years. Financial support by several projects is acknowledged: MAT201451982-C2-1-R, MAT2014-51982-C2-2-R and MAT2015-69725-REDT from MINECO (including FEDER funding), CELINA COST Action CM1301, Aragón Regional Government through project E26, FP7 Marie Curie Fellowship 3DMAGNANOW, EPSRC Early Career Fellowship EP/M008517/1 and Winton Fellowship. 
1. Bader SD. Colloquium: Opportunities in nanomagnetism. Rev Mod Phys. 2006 JanMar;78(1):1-15. PubMed PMID: WOS:000236516300001. English.

2. Childress JR, Fontana RE. Magnetic recording read head sensor technology. $\mathrm{Cr}$ Phys. 2005 Nov;6(9):997-1012. PubMed PMID: WOS:000234632700008. English.

3. Baibich MN, Broto JM, Fert A, Vandau FN, Petroff F, Eitenne P, et al. Giant Magnetoresistance of (001)Fe/(001) Cr Magnetic Superlattices. Phys Rev Lett. 1988 Nov 21;61(21):2472-5. PubMed PMID: WOS:A1988Q948900022. English.

4. Binasch G, Grunberg P, Saurenbach F, Zinn W. Enhanced Magnetoresistance in Layered Magnetic-Structures with Antiferromagnetic Interlayer Exchange. Phys Rev B. 1989 Mar 1;39(7):4828-30. PubMed PMID: WOS:A1989T686300141. English.

5. Fert A. Nobel Lecture: Origin, development, and future of spintronics. Rev Mod Phys. 2008 Oct-Dec;80(4):1517-30. PubMed PMID: WOS:000262253500011. English.

6. Thompson SM. The discovery, development and future of GMR: The Nobel Prize 2007. J Phys D Appl Phys. 2008 May 7;41(9). PubMed PMID: WOS:000254786700007. English.

7. Chappert C, Fert A, Van Dau FN. The emergence of spin electronics in data storage. Nat Mater. 2007 Nov;6(11):813-23. PubMed PMID: WOS:000250615400018. English.

8. Parkin SSP, Hayashi M, Thomas L. Magnetic domain-wall racetrack memory. Science. 2008 Apr 11;320(5873):190-4. PubMed PMID: WOS:000254836700032. English.

9. Allwood DA, Xiong G, Faulkner CC, Atkinson D, Petit D, Cowburn RP. Magnetic domain-wall logic. Science. 2005 Sep 9;309(5741):1688-92. PubMed PMID: WOS:000231836700033. English.

10. Yamaguchi A, Ono T, Nasu S, Miyake K, Mibu K, Shinjo T. Real-space observation of current-driven domain wall motion in submicron magnetic wires. Phys Rev Lett. 2004 Feb 20;92(7). PubMed PMID: WOS:000189139500052. English.

11. Cros V, Boulle O, Grollier J, Hamzic A, Munoz M, Pereira LG, et al. Spin Transfer Torque: a new method to excite or reverse a magnetization. Cr Phys. 2005 Nov;6(9):956-65. PubMed PMID: WOS:000234632700005. English.

12. Martins VC, Germano J, Cardoso FA, Loureiro J, Cardoso S, Sousa L, et al. Challenges and trends in the development of a magnetoresistive biochip portable platform. Journal of Magnetism and Magnetic Materials. 2010 May-Jun;322(9-12):1655-63. PubMed PMID: WOS:000275746100162. English.

13. Di Michele L, Shelly C, Gallop J, Kazakova O. Single particle detection: Phase control in submicron Hall sensors. Journal of Applied Physics. 2010 Nov 15;108(10). PubMed PMID: WOS:000285005000105. English.

14. Llandro J, Palfreyman JJ, Ionescu A, Barnes CHW. Magnetic biosensor technologies for medical applications: a review. Med Biol Eng Comput. 2010 Oct;48(10):977-98. PubMed PMID: WOS:000282184600005. English.

15. Amaral J, Gaspar J, Pinto V, Costa T, Sousa N, Cardoso S, et al. Measuring brain activity with magnetoresistive sensors integrated in micromachined probe needles. Appl Phys a-Mater. 2013 May;111(2):407-12. PubMed PMID: WOS:000319064800010. English. 16. Xia YN, Rogers JA, Paul KE, Whitesides GM. Unconventional methods for fabricating and patterning nanostructures. Chem Rev. 1999 Jul;99(7):1823-48. PubMed PMID: WOS:000081622800008. English.

17. Martin JI, Nogues J, Liu K, Vicent JL, Schuller IK. Ordered magnetic nanostructures: fabrication and properties. Journal of Magnetism and Magnetic Materials. 2003 Jan;256(1-3):449-501. PubMed PMID: WOS:000180637900056. English.

18. Shiratsuchi Y, Yamamoto M, Bader SD. Magnetism and surface structure of atomically controlled ultrathin metal films. Prog Surf Sci. 2007;82(2-3):121-60. PubMed PMID: WOS:000246590000002. English. 
19. Akerman J, Munoz M, Maicas M, Prieto JL. Stochastic nature of the domain wall depinning in permalloy magnetic nanowires. Phys Rev B. 2010 Aug 31;82(6). PubMed PMID: WOS:000281405800005. English.

20. Khizroev S, Litvinov D. Focused-ion-beam-based rapid prototyping of nanoscale magnetic devices. Nanotechnology. 2004 Mar;15(3):R7-R15. PubMed PMID: WOS:000220530000003. English.

21. Randolph SJ, Fowlkes JD, Rack PD. Focused, Nanoscale Electron-Beam-Induced Deposition and Etching. Critical Reviews in Solid State and Materials Sciences. 2006;31(3):55-89.

22. van Dorp WF, Hagen CW. A critical literature review of focused electron beam induced deposition. Journal of Applied Physics. 2008;104(8):081301.

23. Utke I, Hoffmann P, Melngailis J. Gas-assisted focused electron beam and ion beam processing and fabrication. Journal of Vacuum Science \& Technology B: Microelectronics and Nanometer Structures. 2008;26(4):1197.

24. Huth M, Porrati F, Schwalb C, Winhold M, Sachser R, Dukic M, et al. Focused electron beam induced deposition: A perspective. Beilstein journal of nanotechnology. 2012 Aug 29;3:597-619. PubMed PMID: WOS:000308019300001. English.

25. Utke I, Moshkalev S, Russell P. Nanofabrication using focused ion and electron beams : principles and applications. Oxford ; New York: Oxford University Press; 2012. xvi, 813 p. p.

26. Plank H, Smith DA, Haber T, Rack PD, Hofer F. Fundamental Proximity Effects in Focused Electron Beam Induced Deposition. Acs Nano. 2012 Jan;6(1):286-94. PubMed PMID: WOS:000299368300037. English.

27. van Dorp WF, Beyer A, Mainka M, Golzhauser A, Hansen TW, Wagner JB, et al. Focused electron beam induced processing and the effect of substrate thickness revisited. Nanotechnology. 2013 Aug 30;24(34):345301. PubMed PMID: 23899908.

28. Thorman RM, Kumar TPR, Fairbrother DH, Ingolfsson O. The role of low-energy electrons in focused electron beam induced deposition: four case studies of representative precursors. Beilstein journal of nanotechnology. 2015 Sep 16;6:1904-26. PubMed PMID: WOS:000361349000001. English.

29. De Teresa JM, Fernandez-Pacheco A. Present and future applications of magnetic nanostructures grown by FEBID. Appl Phys a-Mater. 2014 Dec;117(4):1645-58. PubMed PMID: WOS:000345293200006. English.

30. O. Idigoras EN, J. M. Porro, P. Vavassori, A. Chuvilin, A. Berger. FEBID fabrication and magnetic characterization of individual nano-scale and micro-scale Co structures. Nanofabrication. 2014;1(1):23-34.

31. Mulders JJL. Practical precursor aspects for electron beam induced deposition. Nanofabrication. 2014;1:74-9.

32. Lapicki A, Ahmad E, Suzuki T. Ion beam induced chemical vapor deposition (IBICVD) of cobalt particles. Journal of Magnetism and Magnetic Materials. 2002 Feb;240(1-3):47-9. PubMed PMID: WOS:000175813900015. English.

33. Lapicki A, Kang K, Suzuki T. Fabrication of magnetic dot arrays by ion beam induced chemical vapor deposition (IBICVD). Ieee T Magn. 2002 Sep;38(5):2589-91. PubMed PMID: WOS:000178867200229. English.

34. Lau YM, Chee PC, Thong JTL, Ng V. Properties and applications of cobalt-based material produced by electron-beam-induced deposition. Journal of Vacuum Science \& Technology A: Vacuum, Surfaces, and Films. 2002;20(4):1295.

35. Utke I, Cicoira F, Jaenchen G, Hoffmann P, Scandella L, Dwir B, et al. Focused electron beam induced deposition of high resolution magnetic scanning probe tips. Mater Res Soc Symp P. 2002;706:307-12. PubMed PMID: WOS:000177282900046. English. 
36. Utke I, Hoffmann P, Berger R, Scandella L. High-resolution magnetic Co supertips grown by a focused electron beam. Applied Physics Letters. 2002;80(25):4792.

37. Lin KW, Suzuki T, Kang K, Zhang ZG. Fabrication and characterization of cobalt particles by ion-beam induced chemical vapor deposition (MCVD). Nanotech 2003, Vol 3. 2003:17-20. PubMed PMID: WOS:000223047000005. English.

38. Kageyama Y, Lapicki A, Suzuki T. Fabrication of cobalt particles by ion beaminduced chemical vapor deposition (IBICVD). Journal of Magnetism and Magnetic Materials. 2004 May;272:E1343-E4. PubMed PMID: WOS:000202897200524. English.

39. Utke I. Thermal effects during focused electron beam induced deposition of nanocomposite magnetic-cobalt-containing tips. Microelectronic Engineering. 2004;7374:553-8.

40. Boero G, Utke I, Bret T, Quack N, Todorova M, Mouaziz S, et al. Submicrometer Hall devices fabricated by focused electron-beam-induced deposition. Applied Physics Letters. 2005;86(4):042503.

41. Utke I, Michler J, Gasser P, Santschi C, Laub D, Cantoni M, et al. Cross section investigations of compositions and sub-structures of tips obtained by focused electron beam induced deposition. Advanced Engineering Materials. 2005 May;7(5):323-31. PubMed PMID: WOS:000229922900011. English.

42. Fernández-Pacheco A, De Teresa JM, Córdoba R, Ibarra MR. Magnetotransport properties of high-quality cobalt nanowires grown by focused-electron-beam-induced deposition. Journal of Physics D: Applied Physics. 2009;42(5):055005.

43. Fernández-Pacheco A, De Teresa JM, Córdoba R, Ibarra MR, Petit D, Read DE, et al. Domain wall conduit behavior in cobalt nanowires grown by focused electron beam induced deposition. Applied Physics Letters. 2009;94(19):192509.

44. Fernandez-Pacheco A, De Teresa JM, Szkudlarek A, Cordoba R, Ibarra MR, Petit D, et al. Magnetization reversal in individual cobalt micro- and nanowires grown by focusedelectron-beam-induced-deposition. Nanotechnology. 2009 Nov 25;20(47):475704. PubMed PMID: 19858555.

45. Bernau L, Gabureac M, Erni R, Utke I. Tunable Nanosynthesis of Composite Materials by Electron-Impact Reaction. Angew Chem Int Edit. 2010;49(47):8880-4. PubMed PMID: WOS:000286149700008. English.

46. Córdoba R, Sesé J, De Teresa JM, Ibarra MR. High-purity cobalt nanostructures grown by focused-electron-beam-induced deposition at low current. Microelectronic Engineering. 2010;87(5-8):1550-3.

47. Dobrovolskiy OV, Huth M, Shklovskij VA. Anisotropic magnetoresistive response in thin $\mathrm{Nb}$ films decorated by an array of Co stripes. Superconductor Science and Technology. 2010;23(12):125014.

48. Gabureac M, Bernau L, Utke I, Boero G. Granular Co-C nano-Hall sensors by focused-beam-induced deposition. Nanotechnology. 2010 Mar 19;21(11):115503. PubMed PMID: 20173236.

49. Belova LM, Dahlberg ED, Riazanova A, Mulders JJL, Christophersen C, Eckert J. Rapid electron beam assisted patterning of pure cobalt at elevated temperatures via seeded growth. Nanotechnology. 2011 Apr 8;22(14). PubMed PMID: WOS:000287970000006. English.

50. Cordoba R, Fernandez-Pacheco R, Fernandez-Pacheco A, Gloter A, Magen C, Stephan O, et al. Nanoscale chemical and structural study of Co-based FEBID structures by STEM-EELS and HRTEM. Nanoscale research letters. 2011 Nov 15;6:1-6. PubMed PMID: WOS:000298195300001. English. 
51. Dobrovolskiy OV, Begun E, Huth M, Shklovskij VA, Tsindlekht MI. Vortex lattice matching effects in a washboard pinning potential induced by Co nanostripe arrays. Physica C: Superconductivity. 2011;471(15-16):449-52.

52. Dobrovolskiy OV, Huth M, Shklovskij VA. Fabrication of Artificial Washboard Pinning Structures in Thin Niobium Films. Journal of Superconductivity and Novel Magnetism. 2011 Jan;24(1-2):375-80. PubMed PMID: WOS:000289855700060. English.

53. Gabureac MS, Bernau L, Utke I. Nanosynthesis of Tunable Composite Materials by Room-Temperature Pulsed Focused Electron Beam Induced Chemical Vapour Deposition. J Nanosci Nanotechno. 2011 Sep;11(9):7982-7. PubMed PMID: WOS:000296209900061. English.

54. Jaafar M, Iglesias-Freire O, Serrano-Ramon L, Ibarra MR, de Teresa JM, Asenjo A. Distinguishing magnetic and electrostatic interactions by a Kelvin probe force microscopymagnetic force microscopy combination. Beilstein journal of nanotechnology. 2011;2:55260. PubMed PMID: 22003461. Pubmed Central PMCID: 3190625.

55. Jaafar M, Serrano-Ramon L, Iglesias-Freire O, Fernandez-Pacheco A, Ibarra MR, De Teresa JM, et al. Hysteresis loops of individual Co nanostripes measured by magnetic force microscopy. Nanoscale research letters. 2011;6(1):407. PubMed PMID: 21711935. Pubmed Central PMCID: 3211502.

56. Michalik JM, Roddaro S, Casado L, Ibarra MR, De Teresa JM. Quantification and minimization of disorder caused by focused electron beam induced deposition of cobalt on graphene. Microelectronic Engineering. 2011;88(8):2063-5.

57. Mulders JJ, Belova LM, Riazanova A. Electron beam induced deposition at elevated temperatures: compositional changes and purity improvement. Nanotechnology. 2011 Feb 4;22(5):055302. PubMed PMID: 21178259.

58. Sangiao S, De Teresa JM, Ibarra MR, Guillamon I, Suderow H, Vieira S, et al. Andreev reflection under high magnetic fields in ferromagnet-superconductor nanocontacts. Phys Rev B. 2011 Dec 2;84(23). PubMed PMID: WOS:000297764700001. English.

59. Sangiao S, Morellón L, Ibarra MR, De Teresa JM. Ferromagnet-superconductor nanocontacts grown by focused electron/ion beam techniques for current-in-plane Andreev Reflection measurements. Solid State Communications. 2011;151(1):37-41.

60. Serrano-Ramon L, Cordoba R, Rodriguez LA, Magen C, Snoeck E, Gatel C, et al. Ultrasmall Functional Ferromagnetic Nanostructures Grown by Focused Electron-BeamInduced Deposition. Acs Nano. 2011 Oct;5(10):7781-7. PubMed PMID: WOS:000296208700024. English.

61. Belova LM, Hellwig O, Dobisz E, Dahlberg ED. Rapid preparation of electron beam induced deposition Co magnetic force microscopy tips with $10 \mathrm{~nm}$ spatial resolution. Rev Sci Instrum. 2012 Sep;83(9). PubMed PMID: WOS:000309426700034. English.

62. Cordoba R, Sese J, Ibarra MR, De Teresa JM. Autocatalytic growth of Co on pure Co surfaces using Co-2(CO)(8) precursor. Appl Surf Sci. 2012 Dec 15;263:242-6. PubMed PMID: WOS:000311217500039. English.

63. Muthukumar K, Jeschke HO, Valenti R, Begun E, Schwenk J, Porrati F, et al. Spontaneous dissociation of $\mathrm{Co}(2)(\mathrm{CO})(8)$ and autocatalytic growth of $\mathrm{Co}$ on $\mathrm{SiO}(2)$ : A combined experimental and theoretical investigation. Beilstein journal of nanotechnology. 2012;3:546-55. PubMed PMID: 23019550. Pubmed Central PMCID: 3458600.

64. Nikulina E, Idigoras O, Vavassori P, Chuvilin A, Berger A. Magneto-optical magnetometry of individual $30 \mathrm{~nm}$ cobalt nanowires grown by electron beam induced deposition. Applied Physics Letters. 2012 Apr 2;100(14). PubMed PMID: WOS:000302567800043. English.

65. Porrati F, Begun E, Winhold M, Schwalb CH, Sachser R, Frangakis AS, et al. Room temperature L1(0) phase transformation in binary CoPt nanostructures prepared by focused- 
electron-beam-induced deposition. Nanotechnology. 2012 May 11;23(18). PubMed PMID: WOS:000303532900018. English.

66. Fernandez-Pacheco A, Serrano-Ramon L, Michalik JM, Ibarra MR, De Teresa JM, O'Brien L, et al. Three dimensional magnetic nanowires grown by focused electron-beam induced deposition. Sci Rep-Uk. 2013 Mar 20;3. PubMed PMID: WOS:000316317400002. English.

67. Gabureac MS, Bernau L, Boero G, Utke I. Single Superparamagnetic Bead Detection and Direct Tracing of Bead Position Using Novel Nanocomposite Nano-Hall Sensors. Ieee T Nanotechnol. 2013 Sep;12(5):668-73. PubMed PMID: WOS:000324501600004. English.

68. Nikulina E, Idigoras O, Porro JM, Vavassori P, Chuvilin A, Berger A. Origin and control of magnetic exchange coupling in between focused electron beam deposited cobalt nanostructures. Applied Physics Letters. 2013;103(12):123112.

69. Porrati F, Kampken B, Terfort A, Huth M. Fabrication and electrical transport properties of binary $\mathrm{Co}-\mathrm{Si}$ nanostructures prepared by focused electron beam-induced deposition. Journal of Applied Physics. 2013 Feb 7;113(5). PubMed PMID: WOS:000314746200036. English.

70. Rodriguez LA, Magen C, Snoeck E, Gatel C, Marin L, Serrano-Ramon L, et al. Quantitative in situ magnetization reversal studies in Lorentz microscopy and electron holography. Ultramicroscopy. 2013 Nov;134:144-54. PubMed PMID: WOS:000324474900019. English.

71. Rodriguez LA, Magen C, Snoeck E, Serrano-Ramon L, Gatel C, Cordoba R, et al. Optimized cobalt nanowires for domain wall manipulation imaged by in situ Lorentz microscopy. Applied Physics Letters. 2013 Jan 14;102(2). PubMed PMID: WOS:000313670200061. English.

72. Serrano-Ramon L, Fernandez-Pacheco A, Cordoba R, Magen C, Rodriguez LA, Petit $\mathrm{D}$, et al. Improvement of domain wall conduit properties in cobalt nanowires by global gallium irradiation. Nanotechnology. 2013 Aug 30;24(34). PubMed PMID: WOS:000322642900018. English.

73. Serrano-Ramon L, Fernandez-Pacheco A, Ibarra MR, Petit D, Cowburn RP, Tyliszczak T, et al. Modification of domain-wall propagation in Co nanowires via $\mathrm{Ga}+$ irradiation. Eur Phys J B. 2013 Mar;86(3). PubMed PMID: WOS:000317012300025. English.

74. Wu H, Stern LA, Xia D, Ferranti D, Thompson B, Klein KL, et al. Focused helium ion beam deposited low resistivity cobalt metal lines with $10 \mathrm{~nm}$ resolution: implications for advanced circuit editing. Journal of Materials Science: Materials in Electronics. 2013;25(2):587-95.

75. Costanzi BN, Riazanova AV, Dan Dahlberg E, Belova LM. In situ manufacture of magnetic tunnel junctions by a direct-write process. Applied Physics Letters. 2014;104(22):222401.

76. De Teresa JM, Cordoba R. Arrays of Densely Packed Isolated Nanowires by Focused Beam Induced Deposition Plus Ar+ Milling. Acs Nano. 2014 Apr;8(4):3788-95. PubMed PMID: WOS:000334990600074. English.

77. De Teresa JM, Holuj P, Cordoba R, Fernandez-Pacheco R, Michalik JM. Fabrication of cobalt trifluoride (CoF3) phase from metallic cobalt by XeF2-assisted Focused Electron Beam Induced Processing. Microelectronic Engineering. 2014 Aug 1;125:78-82. PubMed PMID: WOS:000338611700016. English.

78. G. Tosolini JM, R. Córdoba, J. M. De Teresa, F. Pérez-Murano, J. Bausells. Magnetic properties of cobalt microwires measured by piezoresistive cantilever magnetometry Nanofabrication. 2014;1(1):80-5. 
79. H. Lavenant VN, O. Klein, G. de Loubens, L. Casado, J. M. De Teresa. Mechanical magnetometry of Cobalt nanospheres deposited by focused electron beam at the tip of ultrasoft cantilevers. Nanofabrication. 2014;1(1):65-73.

80. Lara A, Dobrovolskiy OV, Prieto JL, Huth M, Aliev FG. Magnetization reversal assisted by half antivortex states in nanostructured circular cobalt disks. Applied Physics Letters. 2014 Nov 3;105(18). PubMed PMID: WOS:000345000000046. English.

81. Porrati F, Begun E, Sachser R, Huth M. Spin-dependent transport between magnetic nanopillars through a nano-granular metal matrix. Journal of Physics D: Applied Physics. 2014;47(49):495001.

82. S. Wachter MG, H. D. Wanzenboeck, M. M. Shawrav, D. Belic, E. Bertagnolli. Nitrogen as a carrier gas for regime control in focused electron beam induced deposition. Nanofabrication. 2014;1(1):16-22.

83. Sharma N, Vugts P, Daniels C, Keuning W, Kohlhepp JT, Kurnosikov O, et al. Multi-channel Andreev reflection in Co-W nanocontacts fabricated using focused electron/ion beam induced deposition. Nanotechnology. 2014 Dec 12;25(49):495201. PubMed PMID: 25409909.

84. Begun E, Dobrovolskiy OV, Kompaniiets M, Sachser R, Gspan C, Plank H, et al. Post-growth purification of Co nanostructures prepared by focused electron beam induced deposition. Nanotechnology. 2015 Feb 20;26(7):075301. PubMed PMID: 25620617.

85. Dobrovolskiy OV, Kompaniiets M, Sachser R, Porrati F, Gspan C, Plank H, et al. Tunable magnetism on the lateral mesoscale by post-processing of $\mathrm{Co} / \mathrm{Pt}$ heterostructures. Beilstein journal of nanotechnology. 2015;6:1082-90. PubMed PMID: 26171284. Pubmed Central PMCID: 4464159.

86. Gazzadi GC, Frabboni S. Structural transitions in electron beam deposited Cocarbonyl suspended nanowires at high electrical current densities. Beilstein journal of nanotechnology. 2015 Jun 11;6:1298-305. PubMed PMID: WOS:000356142200001. English.

87. Peinado P, Sangiao S, De Teresa JM. Focused Electron and Ion Beam Induced Deposition on Flexible and Transparent Polycarbonate Substrates. Acs Nano. 2015 Jun;9(6):6139-46. PubMed PMID: WOS:000356988500053. English.

88. Perez-Roldan MJ, Tatti F, Vavassori P, Berger A, Chuvilin A. Segregation of materials in double precursor electron-beam-induced-deposition: a route to functional magnetic nanostructures. Nanotechnology. 2015 Sep 18;26(37):375302. PubMed PMID: 26313638.

89. Pohlit M, Porrati F, Huth M, Ohno Y, Ohno H, Müller J. Nanocluster building blocks of artificial square spin ice: Stray-field studies of thermal dynamics. Journal of Applied Physics. 2015;117(17):17C746.

90. Wolf D, Rodriguez LA, Beche A, Javon E, Serrano L, Magen C, et al. 3D Magnetic Induction Maps of Nanoscale Materials Revealed by Electron Holographic Tomography. Chem Mater. 2015 Oct 13;27(19):6771-8. PubMed PMID: WOS:000362920700037. English.

91. Pohlit M, Porrati F, Huth M, Ohno Y, Ohno H, Muller J. Magnetic stray-field studies of a single Cobalt nanoelement as a component of the building blocks of artificial square spin ice. Journal of Magnetism and Magnetic Materials. 2016 Feb 15;400:206-12. PubMed PMID: WOS:000366157600044. English.

92. Vavassori P, Pancaldi M, Perez-Roldan MJ, Chuvilin A, Berger A. Remote magnetomechanical nanoactuation. Small. 2016.

93. Fernandez-Pacheco A, Serrano-Ramon LE, Tyliszczak T, Chou KW, Cordoba R, Szkudlarek A, et al. Correlation between the magnetic imaging of cobalt nanoconstrictions 
and their magnetoresistance response. Nanotechnology. 2012 Mar 16;23(10). PubMed PMID: WOS:000301174400023. English.

94. Mirbach MF, Saus A, Krings AM, Mirbach MJ. Thermal, Photochemical and Alcohol Catalyzed Formation of $\mathrm{Co} 4(\mathrm{Co}) 12$ from Co2(Co)8. Kinetics and Mechanism. J Organomet Chem. 1981;205(2):229-37. PubMed PMID: WOS:A1981LA00700012. English.

95. Gazzadi GC, Mulders H, Trompenaars P, Ghirri A, Affronte M, Grillo V, et al. Focused Electron Beam Deposition of Nanowires from Cobalt Tricarbonyl Nitrosyl (Co(CO)(3)NO) Precursor. J Phys Chem C. 2011 Oct 13;115(40):19606-11. PubMed PMID: WOS:000295546100020. English.

96. Gazzadi GC, Mulders JJL, Trompenaars P, Ghirri A, Rota A, Affronte M, et al. Characterization of a new cobalt precursor for focused beam deposition of magnetic nanostructures. Microelectronic Engineering. 2011;88(8):1955-8.

97. Rosenberg SG, Barclay M, Fairbrother DH. Electron Beam Induced Reactions of Adsorbed Cobalt Tricarbonyl Nitrosyl (Co(CO)3NO) Molecules. The Journal of Physical Chemistry C. 2013;117(31):16053-64.

98. Papp P, Engmann S, Kucera M, Stano M, Matejcik S, Ingolfsson O. An experimental and theoretical study on structural parameters and energetics in ionization and dissociation of cobalt tricarbonyl nitrosyl. Int J Mass Spectrom. 2013 Dec 15;356:24-32. PubMed PMID: WOS:000328432200004. English.

99. Vollnhals F, Drost M, Tu F, Carrasco E, Spath A, Fink RH, et al. Electron-beam induced deposition and autocatalytic decomposition of $\mathrm{Co}(\mathrm{CO})(3) \mathrm{NO}$. Beilstein journal of nanotechnology. 2014 Jul 30;5:1175-85. PubMed PMID: WOS:000339910600001. English.

100. Ervin MH, Nichols BM. Electron beam induced deposition of cobalt for use as single- and multiwalled carbon nanotube growth catalyst. Journal of Vacuum Science \& Technology B: Microelectronics and Nanometer Structures. 2009;27(6):2982.

101. Kunz RR, Mayer TM. Catalytic Growth-Rate Enhancement of Electron-Beam Deposited Iron Films. Applied Physics Letters. 1987 Apr 13;50(15):962-4. PubMed PMID: WOS:A1987G780000006. English.

102. Kunz RR, Allen TE, Mayer TM. Selective Area Deposition of Metals Using LowEnergy Electron-Beams. J Vac Sci Technol B. 1987 Sep-Oct;5(5):1427-31. PubMed PMID: WOS:A1987K494900023. English.

103. Shimojo M, Takeguchi M, Tanaka M, Mitsuishi K, Furuya K. Electron beaminduced deposition using iron carbonyl and the effects of heat treatment on nanostructure. Applied Physics A. 2004;79(8):1869-72.

104. Zhang W, Shimojo M, Takeguchi M, Che RC, Furuya K. Generation Mechanism andin situ Growth Behavior of $\alpha$-Iron Nanocrystals by Electron Beam Induced Deposition. Advanced Engineering Materials. 2006;8(8):711-4.

105. Bruk MA, Zhikharev EN, Grigor'ev EI, Spirin AV, Kal'nov VA, Kardash IE. Focused electron beam-induced deposition of iron- and carbon-containing nanostructures from triiron dodecacarbonyl vapor. High Energ Chem+. 2005 Mar-Apr;39(2):65-8. PubMed PMID: WOS:000228153300003. English.

106. Takeguchi M, Shimojo M, Che R, Furuya K. Fabrication of a nano-magnet on a piezo-driven tip in a TEM sample holder. Journal of Materials Science. 2006;41(9):2627-30. 107. Lavrijsen R, Cordoba R, Schoenaker FJ, Ellis TH, Barcones B, Kohlhepp JT, et al. Fe:O:C grown by focused-electron-beam-induced deposition: magnetic and electric properties. Nanotechnology. 2011 Jan 14;22(2):025302. PubMed PMID: 21135470.

108. Botman A, Mulders JJ, Hagen CW. Creating pure nanostructures from electronbeam-induced deposition using purification techniques: a technology perspective. Nanotechnology. 2009 Sep 16;20(37):372001. PubMed PMID: 19706953. 
109. Lukasczyk T, Schirmer M, Steinruck HP, Marbach H. Electron-beam-induced deposition in ultrahigh vacuum: lithographic fabrication of clean iron nanostructures. Small. 2008 Jun;4(6):841-6. PubMed PMID: 18457333.

110. Porrati F, Pohlit M, Muller J, Barth S, Biegger F, Gspan C, et al. Direct writing of CoFe alloy nanostructures by focused electron beam induced deposition from a heteronuclear precursor. Nanotechnology. 2015 Dec 27;26(47):475701. PubMed PMID: 26535785.

111. Perentes A, Sinicco G, Boero G, Dwir B, Hoffmann P. Focused electron beam induced deposition of nickel. Journal of Vacuum Science \& Technology B: Microelectronics and Nanometer Structures. 2007;25(6):2228.

112. Córdoba R, Barcones B, Roelfsema E, Verheijen MA, Mulders JJL, Trompenaars PHL, et al. Functional nickel-based deposits synthesized by focused beam induced processing. Nanotechnology. 2016;27:065303.

113. Xu QY, Kageyama Y, Suzuki T. Ion-beam-induced chemical-vapor deposition of FePt and CoPt particles. Journal of Applied Physics. 2005;97(10):10K308.

114. Pogorelov YGaS, T. Fabrication of Alloy FeCoPt Particles by IBICVD and Their Characterization. IEEE Transactions on Magentics. 2007;43:888-90.

115. Dobrovolskiy OV, Huth M, Shklovskij VA. Fabrication of Artificial Washboard Pinning Structures in Thin Niobium Films. Journal of Superconductivity and Novel Magnetism. 2010;24(1-2):375-80.

116. Shimojo M, Zhang W, Takeguchi M, Tanaka M, Mitsuishi K, Furuya K. Nanodot and nanorod formation in electron-beam-induced deposition using iron carbonyl. Jpn J Appl Phys 1. 2005 Jul;44(7B):5651-3. PubMed PMID: WOS:000232029300074. English.

117. Takeguchi M, Shimojo M, Furuya K. Fabrication of magnetic nanostructures using electron beam induced chemical vapour deposition. Nanotechnology. 2005;16(8):1321-5.

118. Takeguchi M, Shimojo M, Furuya K. Fabrication of alpha-iron and iron carbide nanostructures by electron-beam induced chemical vapor deposition and postdeposition heat treatment. Jpn J Appl Phys 1. 2005 Jul;44(7B):5631-4. PubMed PMID: WOS:000232029300069. English.

119. Tanaka M, Chu F, Shimojo M, Takeguchi M, Mitsuishi K, Furuya K. Position- and size-controlled fabrication of iron silicide nanorods by electron-beam-induced deposition using an ultrahigh-vacuum transmission electron microscope. Applied Physics Letters. 2005;86(18):183104.

120. Tanaka M, Shimojo M, Takeguchi M, Mitsuishi K, Furuya K. Formation of iron nano-dot arrays by electron beam-induced deposition using an ultrahigh vacuum transmission electron microscope. J Cryst Growth. 2005 Feb 15;275(1-2):E2361-E6. PubMed PMID: WOS:000208324600381. English.

121. Che RC, Takeguchi M, Shimojo M, Zhang W, Furuya K. Fabrication and electron holography characterization of FePt alloy nanorods. Applied Physics Letters. 2005;87(22):223109.

122. Shimojo M, Takeguchi M, Furuya K. Formation of crystalline iron oxide nanostructures by electron beam-induced deposition at room temperature. Nanotechnology. 2006;17(15):3637-40.

123. Takeguchi M, Shimojo M, Mitsuishi K, Tanaka M, Che R, Furuya K. Fabrication of nanostructures with different iron concentration by electron beam induced deposition with a mixture gas of iron carbonyl and ferrocene, and their magnetic properties. Journal of Materials Science. 2006;41(14):4532-6.

124. Zhang W, Shimojo M, Takeguchi M, Furuya K. Electron beam-induced formation of nanosized $\alpha$-Fe crystals. Journal of Materials Science. 2006;41(9):2577-80. 
125. Zhang W, Che R, Takeguchi M, Shimojo M, Furuya K. Formation of Fe-Pt intermetallic phase in nanostructures by electron-beam-induced deposition and postdeposition alloying processes. Surf Interface Anal. 2006 Dec;38(12-13):1527-9. PubMed PMID: WOS:000243303500001. English.

126. Tanaka M, Chu F, Shimojo M, Takeguchi M, Mitsuishi K, Furuya K. Formation of iron silicide nano-islands on Si substrates by metal organic chemical vapor deposition under electron beams. Journal of Materials Science. 2006 May;41(9):2667-71. PubMed PMID: WOS:000237655600021. English.

127. Shimojo M, Takeguchi M, Mitsuishi K, Tanaka M, Furuya K. Mechanisms of Crystalline Iron Oxide Formation in Electron Beam-Induced Deposition. Japanese Journal of Applied Physics. 2007;46(9B):6247-9.

128. Takeguchi M, Shimojo M, Furuya K. Nanostructure fabrication by electron-beaminduced deposition with metal carbonyl precursor and water vapor. Jpn J Appl Phys 1. 2007 Sep;46(9B):6183-6. PubMed PMID: WOS:000250066700015. English.

129. Tanaka M, Mitsuishi K, Takeguchi M, Shimojo M, Furuya K, Koguchi N. ElectronBeam-Induced Deposition of Fe Nanoparticles and Thin Films on SrTiO3Substrates. Japanese Journal of Applied Physics. 2007;46(9B):6243-6.

130. Hochleitner G, Wanzenboeck HD, Bertagnolli E. Electron beam induced deposition of iron nanostructures. Journal of Vacuum Science \& Technology B: Microelectronics and Nanometer Structures. 2008;26(3):939.

131. Lukasczyk T, Schirmer M, Steinruck HP, Marbach H. Generation of clean iron structures by electron-beam-induced deposition and selective catalytic decomposition of iron pentacarbonyl on $\mathrm{Rh}(110)$. Langmuir : the ACS journal of surfaces and colloids. 2009 Oct 6;25(19):11930-9. PubMed PMID: 19630434.

132. Porrati F, Sachser R, Walz MM, Vollnhals F, Steinrück HP, Marbach H, et al. Magnetotransport properties of iron microwires fabricated by focused electron beam induced autocatalytic growth. Journal of Physics D: Applied Physics. 2011;44(42):425001.

133. Schirmer M, Walz MM, Papp C, Kronast F, Gray AX, Balke B, et al. Fabrication of layered nanostructures by successive electron beam induced deposition with two precursors: protective capping of metallic iron structures. Nanotechnology. 2011 Nov 25;22(47). PubMed PMID: WOS:000296759000005. English.

134. Gavagnin M, Wanzenboeck HD, Belic D, Bertagnolli E. Synthesis of Individually Tuned Nanomagnets for Nanomagnet Logic by Direct Write Focused Electron Beam Induced Deposition. Acs Nano. 2013 Jan;7(1):777-84. PubMed PMID: WOS:000314082800083. English.

135. Vollnhals F, Woolcot T, Walz MM, Seiler S, Steinruck HP, Thornton G, et al. Electron Beam-Induced Writing of Nanoscale Iron Wires on a Functional Metal Oxide. The journal of physical chemistry C, Nanomaterials and interfaces. 2013 Aug 29;117(34):176749. PubMed PMID: 24159366. Pubmed Central PMCID: 3805331.

136. Gavagnin M, Wanzenboeck HD, Belic D, Shawrav MM, Persson A, Gunnarsson K, et al. Magnetic force microscopy study of shape engineered FEBID iron nanostructures. physica status solidi (a). 2014;211(2):368-74.

137. Gavagnin M, Wanzenboeck HD, Shawrav MM, Belic D, Wachter S, Waid S, et al. Focused Electron Beam-Induced CVD of Iron: a Practical Guide for Direct Writing. Chem Vapor Depos. 2014 Sep;20(7-9):243-50. PubMed PMID: WOS:000342069800007. English. 138. Gavagnin M, Wanzenboeck HD, Wachter S, Shawrav MM, Persson A, Gunnarsson $\mathrm{K}$, et al. Free-standing magnetic nanopillars for 3D nanomagnet logic. ACS applied materials \& interfaces. 2014 Nov 26;6(22):20254-60. PubMed PMID: 25296008. Pubmed Central PMCID: 4251043. 
139. Shawrav MM, Belic D, Gavagnin M, Wachter S, Schinnerl M, Wanzenboeck HD, et al. Electron Beam-Induced CVD of Nanoalloys for Nanoelectronics. Chem Vapor Depos. 2014 Sep;20(7-9):251-7. PubMed PMID: WOS:000342069800008. English.

140. Ribar A, Danko M, Orszagh J, da Silva FF, Utke I, Matejcik S. Dissociative excitation study of iron pentacarbonyl molecule. Eur Phys J D. 2015 Apr 23;69(4). PubMed PMID: WOS:000354200200001. English.

141. Pogoryelov Y, Suzuki T. Fabrication of alloy FeCoPt particles by IBICVD and their characterization. Ieee $\mathrm{T}$ Magn. 2007 Feb;43(2):888-90. PubMed PMID: WOS:000244011300066. English.

142. Córdoba R, Lavrijsen R, Fernández-Pacheco A, Ibarra MR, Schoenaker F, Ellis T, et al. Giant anomalous Hall effect in Fe-based microwires grown by focused-electron-beaminduced deposition. Journal of Physics D: Applied Physics. 2012;45(3):035001.

143. Franken JH, van der Heijden MAJ, Ellis TH, Lavrijsen R, Daniels C, McGrouther D, et al. Beam-Induced Fe Nanopillars as Tunable Domain-Wall Pinning Sites. Advanced Functional Materials. 2014;24(23):3508-14.

144. Rodriguez LA, Deen L, Cordoba R, Magen C, Snoeck E, Koopmans B, et al. Influence of the shape and surface oxidation in the magnetization reversal of thin iron nanowires grown by focused electron beam induced deposition. Beilstein journal of nanotechnology. 2015 Jun 15;6:1319-31. PubMed PMID: WOS:000356142400001. English. 145. Szkudlarek A, Szmyt W, Kapusta C, Utke I. Lateral resolution in focused electron beam-induced deposition: scaling laws for pulsed and static exposure. Applied Physics A. 2014;117(4):1715-26.

146. Silvis-Cividjian N, Hagen CW, Kruit P. Spatial resolution limits in electron-beaminduced deposition. Journal of Applied Physics. 2005;98(8):084905.

147. Walz MM, Vollnhals F, Schirmer M, Steinruck HP, Marbach H. Generation of clean iron nanocrystals on an ultra-thin SiOx film on Si(001). Phys Chem Chem Phys. 2011;13(38):17333-8. PubMed PMID: WOS:000295128000048. English.

148. Marbach H. Electron beam induced surface activation: a method for the lithographic fabrication of nanostructures via catalytic processes. Applied Physics A. 2014; 117:987-95.

149. Walz MM, Vollnhals F, Rietzler F, Schirmer M, Steinruck HP, Marbach H. Investigation of proximity effects in electron microscopy and lithography. Applied Physics Letters. 2012 Jan 30;100(5). PubMed PMID: WOS:000300065300074. English.

150. Walz MM, Vollnhals F, Rietzler F, Schirmer M, Kunzmann A, Steinruck HP, et al. Thin membranes versus bulk substrates: investigation of proximity effects in focused electron beam-induced processing. J Phys D Appl Phys. 2012 Jun 6;45(22). PubMed PMID: WOS:000305175100016. English.

151. Vollnhals F, Woolcot T, Walz MM, Seiler S, Steinruck HP, Thornton G, et al. Electron Beam-Induced Writing of Nanoscale Iron Wires on a Functional Metal Oxide. J Phys Chem C. 2013 Aug 29;117(34):17674-9. PubMed PMID: WOS:000323917300035. English.

152. Tanaka M, Chu F, Shimojo M, Takeguchi M, Mitsuishi K, Furuya K. Position- and size-controlled fabrication of iron silicide nanorods by electron-beam-induced deposition using an ultrahigh-vacuum transmission electron microscope. Applied Physics Letters. 2005 May 2;86(18). PubMed PMID: WOS:000229288700045. English.

153. Tanaka M, Han M, Takeguchi M, Chu F, Shimojo M, Mitsuishi K, et al. Morphology of iron silicide nanorods formed by electron-beam-induced deposition using ultrahighvacuum transmission electron microscope. Jpn J Appl Phys 1. 2005 Jul;44(7B):5635-8. PubMed PMID: WOS:000232029300070. English.

154. Serrano-Esparza I MJ, Ibarra R, De Teresa, JM. Precursor competition in focusedion-beam-induced co-deposition from W(CO)6 and C10H8. Science Letters. 2015;4:127. 
155. van Dorp WF, van Someren B, Hagen CW, Kruit P, Crozier PA. Approaching the resolution limit of nanometer-scale electron beam-induced deposition. Nano Lett. 2005 Jul;5(7):1303-7. PubMed PMID: WOS:000230571300020. English.

156. Ross C. Patterned magnetic recording media. Ann Rev Mater Res. 2001;31:203-35. PubMed PMID: WOS:000171808700010. English.

157. Castagne M, Benfedda M, Lahimer S, Falgayrettes P, Fillard JP. Near field optical behaviour of C supertips. Ultramicroscopy. 1999 Apr;76(4):187-94. PubMed PMID: WOS:000079558900003. English.

158. Rugar D, Mamin HJ, Guethner P, Lambert SE, Stern JE, Mcfadyen I, et al. Magnetic Force Microscopy - General-Principles and Application to Longitudinal Recording Media. Journal of Applied Physics. 1990 Aug 1;68(3):1169-83. PubMed PMID: WOS:A1990DP61600042. English.

159. Lee I, Obukhov Y, Xiang G, Hauser A, Yang FY, Banerjee P, et al. Nanoscale scanning probe ferromagnetic resonance imaging using localized modes. Nature. 2010 Aug 12;466(7308):845-8. PubMed PMID: WOS:000280766100031. English.

160. Pigeau B, Hahn C, de Loubens G, Naletov VV, Klein O, Mitsuzuka K, et al. Measurement of the Dynamical Dipolar Coupling in a Pair of Magnetic Nanodisks Using a Ferromagnetic Resonance Force Microscope. Phys Rev Lett. 2012 Dec 10;109(24). PubMed PMID: WOS:000312068300037. English.

161. Chia HJ, Guo F, Belova LM, McMichael RD. Two-dimensional spectroscopic imaging of individual ferromagnetic nanostripes. Phys Rev B. 2012 Nov 6;86(18). PubMed PMID: WOS:000310840400004. English.

162. Chia HJ, Guo F, Belova LM, McMichael RD. Spectroscopic defect imaging in magnetic nanostructure arrays. Applied Physics Letters. 2012 Jul 23;101(4). PubMed PMID: WOS:000306944700058. English.

163. Chia HJ, Guo F, Belova LM, McMichael RD. Nanoscale Spin Wave Localization Using Ferromagnetic Resonance Force Microscopy. Phys Rev Lett. 2012 Feb 24;108(8). PubMed PMID: WOS:000300670300011. English.

164. Guo F, Belova LM, McMichael RD. Spectroscopy and Imaging of Edge Modes in Permalloy Nanodisks. Phys Rev Lett. 2013 Jan 3;110(1). PubMed PMID: WOS:000313028500017. English.

165. Guo F, Belova LM, McMichael RD. Parametric pumping of precession modes in ferromagnetic nanodisks. Phys Rev B. 2014 Mar 26;89(10). PubMed PMID: WOS:000333383100001. English.

166. Guo F, Belova LM, McMichael RD. Nonlinear ferromagnetic resonance shift in submicron Permalloy ellipses. Phys Rev B. 2015 Feb 27;91(6). PubMed PMID: WOS:000350317300016. English.

167. Moritz J, Rodmacq B, Auffret S, Dieny B. Extraordinary Hall effect in thin magnetic films and its potential for sensors, memories and magnetic logic applications. J Phys D Appl Phys. 2008 Jul 7;41(13). PubMed PMID: WOS:000256928100033. English.

168. Sandhu A, Kurosawa K, Dede M, Oral A. $50 \mathrm{~nm}$ Hall sensors for room temperature scanning Hall probe microscopy. Jpn J Appl Phys 1. 2004 Feb;43(2):777-8. PubMed PMID: WOS:000220401000074. English.

169. Gabureac MS, Alvarez LS, Marrows CH. Co/Pt Hall sensors for low field detection. Procedia Chem. 2009;1(1):851-4. PubMed PMID: WOS:000275995600348. English.

170. Liu T, Lacour D, Montaigne F, Le Gall S, Hehn M, Hauet T. Extraordinary Hall effect based magnetic logic applications. Applied Physics Letters. 2015 Feb 2;106(5). PubMed PMID: WOS:000349611800038. English. 
171. Cowburn RP, Allwood DA, Xiong G, Cooke MD. Domain wall injection and propagation in planar Permalloy nanowires. Journal of Applied Physics. 2002 May 15;91(10):6949-51. PubMed PMID: WOS:000175575100047. English.

172. Wolf SA, Awschalom DD, Buhrman RA, Daughton JM, von Molnar S, Roukes ML, et al. Spintronics: A spin-based electronics vision for the future. Science. 2001 Nov 16;294(5546):1488-95. PubMed PMID: WOS:000172240500038. English.

173. Zutic I, Fabian J, Das Sarma S. Spintronics: Fundamentals and applications. Rev Mod Phys. 2004 Apr;76(2):323-410. PubMed PMID: WOS:000222471500001. English.

174. $\mathrm{Hu} \mathrm{JM}, \mathrm{Li} \mathrm{Z}$, Chen LQ, Nan CW. High-density magnetoresistive random access memory operating at ultralow voltage at room temperature. Nat Commun. 2011 Nov;2. PubMed PMID: WOS:000297686500040. English.

175. Lee YM, Hayakawa J, Ikeda S, Matsukura F, Ohno H. Effect of electrode composition on the tunnel magnetoresistance of pseudo-spin-valve magnetic tunnel junction with a MgO tunnel barrier. Applied Physics Letters. 2007 May 21;90(21). PubMed PMID: WOS:000246775900054. English.

176. De Teresa JM, Barthelemy A, Fert A, Contour JP, Montaigne F, Seneor P. Role of metal-oxide interface in determining the spin polarization of magnetic tunnel junctions. Science. 1999 Oct 15;286(5439):507-9. PubMed PMID: WOS:000083121200053. English.

177. Perez-Willard F, Cuevas JC, Surgers C, Pfundstein P, Kopu J, Eschrig M, et al. Determining the current polarization in Al/Co nanostructured point contacts. Phys Rev B. 2004 Apr;69(14). PubMed PMID: WOS:000221426200012. English.

178. Wang RF, Nisoli C, Freitas RS, Li J, McConville W, Cooley BJ, et al. Artificial 'spin ice' in a geometrically frustrated lattice of nanoscale ferromagnetic islands. Nature. 2006 Jan 19;439(7074):303-6. PubMed PMID: WOS:000234682100037. English.

179. Imre A, Csaba G, Ji L, Orlov A, Bernstein GH, Porod W. Majority logic gate for magnetic quantum-dot cellular automata. Science. 2006 Jan 13;311(5758):205-8. PubMed PMID: WOS:000234722200035. English.

180. Niemier MT, Bernstein GH, Csaba G, Dingler A, Hu XS, Kurtz S, et al. Nanomagnet logic: progress toward system-level integration. J Phys-Condens Mat. 2011 Dec 14;23(49). PubMed PMID: WOS:000298142200002. English.

181. Guillamon I, Suderow H, Vieira S, Fernandez-Pacheco A, Sese J, Cordoba R, et al. Nanoscale superconducting properties of amorphous W-based deposits grown with a focused-ion-beam. New J Phys. 2008 Sep 5;10. PubMed PMID: WOS:000258928300002. English.

182. Barzola-Quiquia J, Dusari S, Chiliotte C, Esquinazi P. Andreev Reflection and Granular Superconductivity Features Observed in Mesoscopic Samples Using Amorphous Tungsten Carbide Superconductors. Journal of Superconductivity and Novel Magnetism. 2011 Jan;24(1-2):463-9. PubMed PMID: WOS:000289855700074. English.

183. Mackus AJM, Mulders JJL, van de Sanden MCM, Kessels WMM. Local deposition of high-purity Pt nanostructures by combining electron beam induced deposition and atomic layer deposition. Journal of Applied Physics. 2010 Jun 1;107(11). PubMed PMID: WOS:000278907100179. English.

184. Mackus AJM, Dielissen SAF, Mulders JJL, Kessels WMM. Nanopatterning by direct-write atomic layer deposition. Nanoscale. 2012;4(15):4477-80. PubMed PMID: WOS:000306324000022. English.

185. Mackus AJM, Thissen NFW, Mulders JJL, Trompenaars PHF, Verheijen MA, Bol AA, et al. Direct-Write Atomic Layer Deposition of High-Quality Pt Nanostructures: Selective Growth Conditions and Seed Layer Requirements. J Phys Chem C. 2013 May 23;117(20):10788-98. PubMed PMID: WOS:000319649400065. English. 
186. Melzer M, Makarov D, Calvimontes A, Karnaushenko D, Baunack S, Kaltofen R, et al. Stretchable Magnetoelectronics. Nano Lett. 2011 Jun;11(6):2522-6. PubMed PMID: WOS:000291322600057. English.

187. T. DEUaHJ. Electron-Beam-Induced Deposition of Platinum from a Liquid Precursor. Nano Lett. 2009;9:2715-8.

188. Berger A, de la Osa RA, Suszka AK, Pancaldi M, Saiz JM, Moreno F, et al. Enhanced Magneto-Optical Edge Excitation in Nanoscale Magnetic Disks. Phys Rev Lett. 2015 Oct 30;115(18). PubMed PMID: WOS:000363788400008. English.

189. Hirohata A, Takanashi K. Future perspectives for spintronic devices. J Phys D Appl Phys. 2014 May 14;47(19). PubMed PMID: WOS:000335517400001. English.

190. Lavrijsen R, Lee JH, Fernandez-Pacheco A, Petit DCMC, Mansell R, Cowburn RP. Magnetic ratchet for three-dimensional spintronic memory and logic. Nature. 2013 Jan 31;493(7434):647-50. PubMed PMID: WOS:000314219600051. English. 